\title{
Mechanical Behavior of Fiber Reinforced SiC/RBSN Ceramic Matrix Composites: Theory and Experiment
}

\author{
Abhisak Chulya \\ Cleveland State University \\ Cleveland, Ohio
}

John P. Gyekenyesi

Lewis Research Center

Cleveland, Ohio

and

Ramakrishna T. Bhatt

Propulsion Directorate

U.S. Army Aviation Systems Command

Lewis Research Center

Cleveland, Ohio

Prepared for the

36th International Gas Turbine and Aeroengine Congress and Exposition sponsored by the American Society of Mechanical Engineers Orlando, Florida, June 3-6, 1991 
Trade names or manufacturers' names are used in this report for identification only. This usage does not constitute an official endorsement, either expressed or implied, by the National Aeronautics and Space Administration. 


\title{
MECHANICAL BEHAVIOR OF FIBER REINFORCED SiC/RBSN CERAMIC MATRIX
}

\section{COMPOSITES: THEORY AND EXPERIMENT}

\author{
Abhisak Chulya* \\ Department of Civil Engineering \\ Cleveland State University \\ Cleveland, Ohio 44115 \\ John P. Gyekenyesi \\ Structural Integrity Branch \\ Lewis Research Center \\ Cleveland, Ohio 44135 \\ and \\ Ramakrishna T. Bhatt \\ Propulsion Directorate \\ U.S. Army Aviation Systems Command \\ Lewis Research Center \\ Cleveland, Ohio 44135
}

\section{SUMMARY}

The mechanical behavior of continuous fiber reinforced SiC/RBSN composites with various fiber contents is evaluated. Both catastrophic and noncatastrophic failures are observed in tensile specimens. Damage and failure mechanisms are identified via in-situ monitoring using NDE techniques throughout the loading history. Effects of fiber/matrix interface debonding (splitting) parallel to the fibers are discussed. Statistical failure behavior of fibers is also observed, especially when the interface is weak. Micromechanical models incorporating residual stresses to calculate the critical matrix cracking strength, ultimate strength and work of pull-out are reviewed and used to predict composite response. For selected test problems, experimental measurements are compared to analytical predictions.

\section{INTRODUCTION}

There is need for strong, tough and sufficiently stable continuous fiberreinforced ceramic matrix composites (CMC) which can survive in oxidizing environments at temperatures approaching $1600{ }^{\circ} \mathrm{C}$. Monofilament silicon carbide fiber in a reaction bonded silicon nitride matrix ( $\mathrm{SiC} / \mathrm{RBSN}$ ) is a promising candidate CMC material for these harsh conditions that often arise in advanced aerospace applications. It is also necessary to have micromechanical models which account for the observed failure behavior and allow tailoring of composites for optimal properties.

Currently, we have an adequate understanding of the mechanical behavior of unidirectional fiber-reinforced CMCs that incorporate small diameter Nicalon ${ }^{1}$ fibers into glass or glass-ceramic matrices, particularly when they are loaded in the fiber

*NASA Resident Research Associate at Lewis Research Center.

${ }^{\mathbf{1}}$ icalon, Nippon Carbon, Tokyo, Japan. 
direction (Prewo and Brennan, 1980; Prewo and Brennan, 1982; Brennan and Prewo, 1982; and Prewo, 1986). We can also demonstrate the influence of fiber/matrix interfaces and a variety of fiber coatings on the behavior of these composite systems (Kerans et al., 1989). Micromechanical models that include the fiber/matrix interface effects correlate well with experimental results (Aveston et al., 1971; Budiansky et al., 1986; Marshall et al., 1985; and McCartney, 1987). However, understanding of failure mechanisms and the development and validation of analytical deformation and fracture models are not mature for SiC/RBSN. We especially lack sufficient knowledge of the initiation and propagation of matrix cracks and fiber breakage. This lack of understanding also hinders composite development which primarily depends on obtaining optimal interface properties and maintaining high fiber strength at elevated temperatures.

The overall mechanical behavior is very complex and involves a large number of independent variables at the microstructural level. Fiber/matrix interfaces that are too weak may cause fiber/matrix interface debonding (splitting). Fiber/matrix interfaces that are too strong may prevent the multiple matrix cracking phenomenon and induce catastrophic failure. Fiber strength also plays a critical role. If the fibers are sufficiently strong and uniform with optimized interfaces, cracks will propagate first only through the matrix and the fibers will likely fail later between the crack surfaces. The composite will fail as predicted by existing micromechanical theories. If the fibers are weak and nonuniform, they will tend to fail throughout the bridging zone and also away from the growing macro crack. In this latter case the fibers will break in a random, statistical manner and continue to bridge the cracks during pull-out.

The objectives of this work were (1) to investigate and understand the mechanical behavior of SiC/RBSN composites throughout their loading history, (2) to study the effects of fiber/matrix interface debonding, (3) to identify the occurrence and nature of damage and failure mechanisms, and (4) to validate micromechanical models so that they can be further developed and optimized.

Both experimental and theoretical studies were made. Test coupons of 1-, 3-, 5- and 8-ply unidirectional SiC/RBSN composites were loaded to failure under tension. Characterization of damage and failure mechanisms was performed through in-situ monitoring using an acoustic emission ( $\mathrm{AE}$ ) technique. An $\mathrm{x}$-radiographic technique was also used to monitor all tests at different load levels and to confirm the $\mathrm{AE}$ results. Interfacial shear strength was obtained from the matrix crack spacing method. Micromechanical models for predicting the critical matrix cracking strength were examined. A parametric study was performed to determine the effect of selected constituents. The ultimate strength and work of pull-out based on weakest link statistics were evaluated and compared with experimental strength data. The main contribution presented herein is a comprehensive study which predicts and measures the critical points in the primary composite tensile stress-strain curve of a unidirectional lamina. 


\section{EXPERIMENTAL PROCEDURES}

\section{Materials}

SiC/RBSN composite tensile specimens were fabricated using SCS-6 SiC fiber monofilaments from Textron Specialty Materials ${ }^{2}$ and high purity silicon powder. The fibers were produced by chemical vapor deposition from methyl-trichlorosilane onto a heated carbon substrate. The outer surface of the $142 \mu \mathrm{m}$ diameter SiC fiber contained two layers of carbon-rich surface coatings which served several objectives. Firstly, it healed surface irregularities on the SiC substrate providing abrasion resistance and improved fiber strength. Secondly, it provided a weak interface for assuring crack deflection and noncatastrophic failure. A schematic diagram of the cross section of the SCS-6 SiC fiber is shown in figure 1(a). Each coating layer is a mixture of amorphous carbon and SiC. The elemental composition of the fiber surface coating is shown in figure 1(b). Scanning electron micrographs of a typical cross section and an enlarged view of the fiber/matrix interface are shown in figure 2. High purity silicon powder obtained from Union Carbide was used for the silicon nitride matrix. The as-received powder contained large agglomerates and required attrition milling to reduce its particle size and to improve its reactivity to nitrogen during a later nitridation step. The average particle size of the attrition milled powder was $0.3 \mu \mathrm{m}$. A detailed description of the composite fabrication is reported elsewhere (Bhatt, 1987).

Test panels of unidirectional laminates containing various number of plies with different fiber volume ratios were fabricated. The length and width of the as-nitrided composite panels were $150 \mathrm{~mm}$ by $50 \mathrm{~mm}$, respectively. The composite matrix contained approximately 30-percent porosity and displayed local density variations around the fibers. The dimensions of the test specimens taken from the panels were $12.74 \mathrm{~mm}$ wide by $125 \mathrm{~mm}$ long. The single ply specimens were $1.05 \mathrm{~mm}$ thick; the 3-ply, $1.64 \mathrm{~mm}$ thick; the 5-ply, $2.4 \mathrm{~mm}$ thick; and the $8-\mathrm{ply}, 2.2 \mathrm{~mm}$ thick. The specimens are described in Table I.

The average room temperature tensile strength of 20 individual as-received SiC fibers with a gauge length of $25 \mathrm{~mm}$ was $3.9 \mathrm{GPa}$ while that of the fibers heated at $1200{ }^{\circ} \mathrm{C}$ in $\mathrm{N}_{2}$ for $40 \mathrm{hr}$ was $2.86 \mathrm{GPa}$ (Bhatt and Phillips, 1988). The elastic modulus of the fibers was $390 \mathrm{GPa}$ (DiCarlo and Williams, 1980) while that of the RBSN matrix was estimated to be $110 \pm 10 \mathrm{GPa}$ (Bhatt and Phillips, 1988). Matrix density and average matrix pore size were $2.3 \mathrm{gm} / \mathrm{cc}$ and $0.025 \mu \mathrm{m}$, respectively (Bhatt and Kiser, 1990). The measured matrix fracture toughness was $2.0 \mathrm{MPam}^{1 / 2}$ (Haggerty, 1989), or in terms of the critical matrix energy release rate, the value was $36 \mathrm{~J} / \mathrm{m}^{2}$. The coefficients of thermal expansion (CTE) up to $1450{ }^{\circ} \mathrm{C}$ were $4.2 \mathrm{E}-6$ and $3.8 \mathrm{E}-6 /{ }^{\circ} \mathrm{C}$ for the fiber and matrix, respectively (Bhatt, 1989).

\section{Testing Procedure}

Tensile tests were conducted with an Instron ${ }^{3} 8562$ loadframe with a 50-kN load cell at a crosshead speed of $0.025 \mathrm{~mm} / \mathrm{min}$. A clip-on extensometer was used in combination with two strain gauges. The latter were glued on the top and bottom parts of the specimen on opposite sides. The piezoelectric transducer for $\mathrm{AE}$ was

${ }^{2}$ Textron Specialty Materials, Lowe11, MA.

${ }^{3}$ Instron Co., Canton, Massachusetts. 
mounted on the upper half of the specimen with Dow Corning high-vacuum grease as the coupling agent. This transducer had a resonant frequency of $250 \mathrm{kHz}$. The bandpass of the preamplifiers and the $\mathrm{AE}$ system was 200 to $400 \mathrm{kHz}$. The $\mathrm{AE}$ and $\mathrm{x}-\mathrm{ray}$ apparatus are shown schematically in figure 3. The definition of an acoustic event is given in figure 4 along with some commonly used terminology. All the specimens were scanned before and after testing by using a $60-\mathrm{kV}$ microfocus $\mathrm{x}$-radiographic system to detect any major flaws or any evidence of major failure events. Another film $\mathrm{x}$-radiographic instrument with $160 \mathrm{kV}$ was mounted on the Instron load frame for in-situ monitoring. The kilovoltage and duration used for each $x$-ray film were different for each specimen, depending on the respective thicknesses. The analog signals for load and strain from the loadframe were fed to the AE system. Stresses were calculated from the imposed loads, while the axial strains in the gauge section were measured by an extensometer. The strain gauges were only used to check bending effects during testing. This was due to the fact that the strain gauges were sensitive only to cracking in a small area around the gauges, and were unlikely to detect first matrix crack formation within the entire gauge length. Failing and failed specimens were also examined visually and photomicrographically.

\section{FAILURE CHARACTERISTICS}

\section{Effect of Fiber Content}

$\mathrm{SiC} / \mathrm{RBSN}$ composites with four different fiber volume ratios were tested. Results are shown in table I. The effect of fiber content on mechanical properties and failure behavior is evident from the listed data. The composite primary modulus, $\mathrm{E}_{c}$, obtained from initial linear portions of the stress-strain curves, increased with increasing fiber volume ratio, $f(f i g .5)$. These data points were best-fitted with a straight line which then was extrapolated to all $f$ values, using the rule of mixtures, $\mathrm{E}_{\mathrm{c}}=\mathrm{fE}_{\mathrm{f}}+(1-\mathrm{f}) \mathrm{E}_{\mathrm{m}}$, where the fiber elastic modulus, $\mathrm{E}_{\mathrm{f}}$, and the average matrix elastic modulus, $\mathrm{E}_{\mathrm{m}}$, were estimated to be 381 and $133 \mathrm{GPa}$, respectively. This fiber modulus was about 2 percent less than the measured value of $390 \mathrm{GPa}$ (DiCarlo and Williams, 1980) while the matrix modulus was 21 percent more than the average value of $110 \pm 10 \mathrm{GPa}$ (Bhatt, 1988). The difference in the matrix modulus is rather high but it could be due to the matrix densities being higher in the low fiber fraction (1- and 3-ply) specimens than in the high fiber fraction (5- and 8-ply) specimens. In addition, in-situ properties do not necessarily agree with individual constituent measurements. The calculated composite primary moduli based on the rule of mixtures were in reasonable agreement with the experimental primary moduli as shown in table $I$.

The effect of fiber content on failure modes was also apparent. Catastrophic failure occurred in the one- and three-ply specimens where the fiber volume ratio was 8 and 16 percent, respectively, for both strong and weak interfaces. In the fiveand eight-ply specimens that had weak interfaces and fiber volume ratios of 19 and 24 percent, respectively, failure was always noncatastrophic. With increasing fiber content, the proportional limit and the ultimate strengths were enhanced significantly. In contrast, the proportional limit strains were essentially unaffected by changes in fiber content. This observation is due to the change in the proportional limit stress being offset by the change in composite stiffness to keep the proportional limit strain unchanged. 


\section{Catastrophic Failure Mechanisms}

Specimens S1A, S1B, and M3A were tested under tension and failed catastrophically. For S1A, x-radiographs taken at increasing loads up to $1330 \mathrm{~N}$ showed no evidence of any failure. Radiographs taken after ultimate failure (fig. 6) showed transverse matrix cracking, fiber fracture, and minimal fiber pull-out. Fiber fractures occurred throughout the gauge length, sometimes twice in the same fiber, due to the statistical behavior of fiber strength and the gauge length being greater than the effective fiber length. Fiber/matrix interface debonding (splitting) and transverse matrix cracking can be observed in the optical photomicrographs (fig. 7). It should be noted that these transverse matrix cracks were not through-the-thickness cracks. It is also evident from the listed loads in figure 6 that the fiber pull-out mechanism occurred only at the very end of the rupture process. As expected, when the fiber content is small, even though the interface is weak, fiber pull-out can not guarantee graceful failure.

The linear stress-strain curve for these specimens and $\mathrm{x}$-ray results taken alone gave no indication of any failure events before the proportional limit or, in this case, the ultimate strength. By contrast, AE results clearly indicated the occurrence of fiber breakage, transverse matrix cracking and fiber/matrix interface debonding throughout the loading history as shown in figure 8 . These major failure mechanisms were identified via three $\mathrm{AE}$ parameters: event duration, peak amplitude, and energy (Chulya et al., 1990). The energy parameter was used to separate microscopic events from macroscopic events. A transverse matrix crack was defined as an event with long duration $(>400 \mu \mathrm{S}$ ) and medium peak amplitude (51 to $70 \mathrm{~dB}$ ) while a fiber fracture event was characterized as short duration $(<400 \mu \mathrm{S})$ and high peak amplitude $(>70 \mathrm{~dB})$. For an interfacial debonding event, high peak amplitude $(>70 \mathrm{~dB})$ and long event duration $(>400 \mu \mathrm{S})$ were detected.

For specimen S1B, which had a strong fiber/matrix interface, the failure mode was also catastrophic but with only one single tranverse through-the-thickness matrix crack. X-radiography showed no sign of fiber breakage scattered throughout the gauge length. Photomicrography showed no evidence of fiber/matrix interface debonding. Transverse matrix cracking and fiber fracture were the only major failure mechanisms observed. These results were confirmed by the AE analysis. As shown in figure 9 by means of a three-dimensional $\mathrm{AE}$ plot, a small single matrix crack occurred first followed by a series of fiber breaks near the crack location until the load reached $2100 \mathrm{~N}$. At this load the small matrix crack propagated all the way through the specimen and catastrophic fiber fractures followed.

The 3-ply SiC/RBSN specimen (M3A) with weak interfaces and 16 percent fiber content also failed catastrophically in tension. 0ptical photomicrography showed multiple transverse matrix cracks (not through-the-thickness but initiating from both sides of the specimen) and multiple fiber/matrix interface debonding. X-radiographic results again showed fiber fracture scattered throughout the gauge length. The plot of $\mathrm{AE}$ event duration and amplitude versus the applied load shown in figure 10 shows that transverse matrix cracking and fiber fracture occurred early in the loading stage and continued throughout the loading history while fiber/matrix interface debonding occurred only after approximately two-thirds of the failure load. The stress-strain curve is linear and does not have the ability or resolution to reflect these failure events. Apparently, the 16-percent fiber content improved the ultimate strength, but still could not prevent catastrophic failure. 


\section{Noncatastrophic Failure Mechanisms}

The load-strain curve and $\mathrm{AE}$ results for a 5 -ply specimen are shown in figure 11. With higher fiber content and weak interfaces, all five-ply composites failed noncatastrophically. X-ray results again did not detect any failure events in the linear region of the load-strain curve. However, AE analysis showed that some matrix cracking, fiber breaking and fiber/matrix interface debonding occurred throughout the linear region (figs. 11 and 12). These phenomena were observed in all 5-ply specimens. Since the fibers started to fail early, it appears that the fiber strength was not adequate, probably because of damage during fabrication. It was also noted from testing specimen S1B that strong interfaces tended to minimize random fiber fracture. These results suggest that, for a high critical matrix cracking stress, fiber strength must be adequate to carry the entire proportional limit load and the interfacial shear strength should be increased.

At the proportional limit, fiber failure occurred extensively but not at any particular surface crack. Instead fiber failure was widely scattered throughout the gauge length. Due to this extensive fiber breakage, ultimate strength was very close to the proportional 1imit for specimen M5B (fig. 11). Photomicrographic examination of the failed specimens (fig. 13) showed no sign of steady state matrix damage, i.e., through-the-thickness transverse cracks. After exceeding the proportional limit, acoustic emission results indicated that matrix cracking and fiber/matrix debonding continued extensively. Beyond the ultimate load, some fiber pull-out took place. Radiography (fig. 13) also showed evidence of similar failure events in the nonlinear region.

The room temperature tensile stress-strain curve for an 8-ply specimen with 24-percent fiber content is shown in figure 14. The proportional limit stress and strain were measured as $195 \mathrm{MPa}$ and 0.124 percent, respectively. After reaching the proportional limit, additional matrix cracks were formed at regular intervals along the gauge length upon further loading. This was evident from radiographs taken during the test (fig. 15 and Baaklini and Bhatt, 1991). This transition region corresponds to stress levels between 200 and $270 \mathrm{MPa}$ in figure 14 . Beyond this region, due to extensive matrix cracking, the deformation of the composite is almost entirely controlled by the fibers. With continued loading beyond the composite ultimate strength, the stress-strain curve showed a drastic drop, resulting in a very short descending tail which indicated the absence of extensive fiber pull-out. Extensive fiber/matrix interface splitting was observed as shown in figure 16 . This, consequently, diminished the pull-out phenomenon. The macroscopic cracks observed by radiography (fig. 15) and optical photomicrography (fig. 16) were now the previously reported through-the-thickness transverse cracks with expected matrix crack spacing. This spacing was used to determine the interfacial shear strength. It is also clear that by increasing the fiber content from 19 to 24 percent, the ultimate strength improved drastically as shown in table I. Such significant improvement is due to both higher fiber content and different processing conditions occurring during fabrication of the 5-ply and the 8-ply specimens. Results from testing these specimens clearly show that with adequate fiber content and optimized interfaces, ideal composite behavior is obtained, that is periodic matrix cracks, high ultimate strength and graceful failure will be observed. 


\title{
IV. INTERFACE CHARACTERISTICS
}

\author{
Fiber/Matrix Interface Debonding
}

Failure mechanisms that were observed in the 1-, 3-, 5- and 8-ply tensile specimens confirm that the strength of the fiber/matrix interface, $\tau$, is very critical to composites behavior. For weak interfaces, the debonding (splitting) mechanism can be described as follows: During tensile loading, the matrix starts to crack and the crack propagates normal to the fiber direction. Once the crack front hits the fiber layer, rather than extending across the interface and around the fibers in the thickness or width directions, the weak interface allows the crack to propagate parallel to the fiber between the fiber and the matrix. This phenomenon occurs only when the fracture energy of the interface is lower than that of the matrix. The location of interface splitting or debonding was mostly between the two carbon-rich coating layers, and not between the matrix and fiber outer coating which usually had a strong chemical bond (Eldridge and Honecy, 1990). Hence, the monofilament fibers contained an engineered interface which, when protected from processing damage, resulted in low values of $\tau$. The resulting interface debonding, especially for low fiber content laminates, not only prevented the occurrence of through-the-thickness matrix cracks, but also reduced the work of fiber pull-out (to be discussed in Section V). This interface debonding also leads to load redistribution from the cracked areas into the undamaged portion of the specimen, causing the fibers to support more load there, which then induces progressive fiber failure below expected levels. For specimen S1B which had strong interfacial shear strength, interface debonding was never detected and the proportional limit strength was much higher than for specimen S1A. Assuming fiber integrity, we conclude that the fracture energy of the matrix, $G_{m}$, should be lower than that of the interface, $G_{i}$, and $G_{i}$ should be lower than that of the fiber, $G_{f}$. This will assure debonding within the desired interface and prevent the crack from kinking into the fiber to cause premature fiber breakage. Therefore, the condition, $G_{m}<G_{i}<G_{f}$, must be satisfied for an optimized composite. The critical ratio of $G_{i}$ to $G_{f}$ was also studied analytically by He and Hutchinson (1989). However, $G_{i}$ is very difficult to determine experimentally because of interface variation from processing conditions as well as the porous nature of the matrix.

\section{Interfacial Frictional Properties}

When interface splitting does not occur, the interfacial frictional stress has the potential to improve the overall strength and toughness of the composite. In order to develop and evaluate micromechanical models that precisely correlate composite behavior with interface frictional properties, interfacial shear strength must be accurately measured. Considerable work meeting this need has been reported (Eldridge and Honecy, 1990; Marshall, 1984; and Marshall and 0liver, 1987). For the $\mathrm{SiC} / \mathrm{RBSN}$ composite with optimized interfaces, the work reported in Eldridge and Honecy (1990) used the push-out test to determine the interfacial shear strength at room temperature. The measured value of $8.1 \pm 0.5 \mathrm{MPa}$ includes the radial residual stress effect which will be discussed below. Of course, $\tau$ can vary significantly within a composite and the push-out technique will give only average values that are subject to processing conditions, matrix porosity, and effects of neighboring fibers. Another approach to measuring $\tau$ is the periodic matrix crack spacing method (Aveston et al., 1971). For valid periodic matrix crack spacing measurements, multiple matrix cracks must occur and they must be through-the-thickness and acrossthe-width. This is defined as a steady-state condition. In reality, these cracks 
are seldom evenly spaced. Therefore, an average value of the crack spacing had to be used. This value, $\mathbf{x}$, measured in specimen M8A by $x$-ray film radiography (fig. 15), was $3.85 \mathrm{~mm}$. In-situ film radiography proved to be a most effective way to measure the crack spacing, since the cracks will close after unloading due to the axial residual compression stress in the matrix. This spacing is a function of the interfacial shear strength, $\tau$, and from equilibrium considerations we have (Aveston et al., 1971)

$$
\tau=\beta R(1-f) E_{m} \sigma_{c r} /\left(2 f E_{c} x\right)
$$

where $\beta$ is a constant equal to 1.337 (Kimber and Keer, 1987), $\sigma_{\mathrm{cr}}$ is the critical matrix cracking stress, and $R$ is the fiber radius. Assuming that $\sigma_{\mathrm{cr}}$ is the proportional limit or microcrack yield stress, the calculated $\tau$ based on the material constituents of specimen M8A was $5 \mathrm{MPa}$. Microstructurally, the interfacial shear strength of this composite is governed by the integrity of the carbon-rich fiber surface coating. For fabrication and heat treatment conditions where the carbon-rich coating remains intact, the composite will display a weak interfacial behavior. Based on our observations, the values of 5 and $8.1 \mathrm{MPa}$ may be too low to yield high critical matrix cracking strength and optimized toughness. Interfacial shear strength is often controlled through heat treatment or with a new coating that has the requisite mechanical properties both at room and high temperatures.

\section{MICROMECHANICAL MODELS}

The above experiments showed that $\mathrm{SiC} / \mathrm{RBSN}$ composites must have sufficient interfacial shear strength for load transfer to occur and to prevent interface splitting or debonding. The interface must be weak enough to allow slipping and substantial pull-out lengths of fibers for toughness. Fiber-reinforced ceramic matrix composites must also have high fiber content, 19 percent or more in this case, with high fiber strength and stiffness for enhancements in composite primary modulus, proportional limit strength, ultimate strength, and work of pul1-out. Once a transverse matrix crack passes through the matrix, the fibers must provide bridging forces across the crack to prevent catastrophic failure. Micromechanical models presented below can predict the failure behavior of the above-described composite throughout its loading history. These models can also be used to obtain the optimum composite properties best suited to the desired applications.

The micromechanical models presented herein are focused on four important design issues: (1) residual stress, (2) critical matrix cracking strength, (3) ultimate strength, and (4) work of pull-out. Single and multiple matrix cracks are considered for both strong and weak interface conditions. The Weibull distribution is linked to the composite ultimate strength and work of pull-out due to the statistically distributed strength properties of fibers observed in the experiments. Comparisons with experimental results are made and the discrepencies are explained.

\section{Residual Stresses}

The processing temperature of $1200{ }^{\circ} \mathrm{C}$ used for the SiC/RBSN composites in this study clearly caused strain mismatches between the fiber and matrix when the composite was cooled to room temperature. This effect should not be neglected. If the coefficients of thermal expansion (CTE) were appreciably different, extensive initial cracking would be observed (Moschler, 1988). The residual stresses arise 
both in the radial direction, i.e., normal to the fiber, and axial direction, i.e., parallel to the fiber. The radial interface pressure, $q$, has a significant effect on the interfacial shear strength which in turn controls the overall failure behavior of the composite. The axial matrix residual stress, $\sigma_{\mathrm{p}}{ }^{\prime}$, will enhance the critical matrix cracking strength if it is in compression. Based on an analysis using the shear lag model, and given isotropic properties for both the fibers and matrix, the following expressions were used to obtain $q$ and $\sigma_{m}$ from the thermal strain mismatch $\varepsilon_{\mathrm{T}}$ (Budiansky et al., 1986):

$$
\begin{gathered}
\left.q=\left(E_{m} / 2 \phi_{1}\right)[1-f) /\left(1-\nu_{m}\right)\right] \varepsilon_{T} \\
\sigma_{m}^{\prime}=\left(E_{m} \phi_{2} / \phi_{1}\right)\left[E_{f} / E_{c}\right]\left[f /\left(1-\nu_{m}\right)\right] \varepsilon_{T}
\end{gathered}
$$

where

$$
\varepsilon_{T}=\left(\alpha_{f}-\alpha_{m}\right) \Delta T
$$

and if we assume that the Poisson's ratio $\nu=\nu_{\mathrm{f}}=\nu_{\mathrm{m}}$,

$$
\begin{gathered}
\phi_{1}=1-0.5[(1-2 \nu) /(1-\nu)]\left(1-\mathrm{E}_{\mathrm{c}} / \mathrm{E}_{f}\right) \\
\phi_{2}=0.5\left(1+\mathrm{E}_{\mathrm{c}} / \mathrm{E}_{f}\right)
\end{gathered}
$$

The subscripts $f$ and $m$ refer to the fiber and matrix, respectively, and $\Delta T$ is the temperature change during cooling. The quantity $\varepsilon_{T}$ is negative when CTE of the fiber is greater than that of the matrix.

When $\mathrm{q}$ is compressive and the Coulomb friction law, $\tau_{\mathbf{R}}=\mu_{\mathrm{q}}$ applies, $\tau_{\mathbf{R}}$ increases the interfacial shear strength. For the SiC/RBSN composite, the fiber has a slightly higher coefficient of thermal expansion than the matrix (Bhatt, 1989). Consequently, the interfacial pressure, q, is tensile which weakens the bond between the fiber and the matrix or that between the carbon layers. To account for this weakening, the Coulomb friction law is used and $\tau_{\mathrm{R}}$ now acts to reduce the frictional shear strength. It is also evident that initial axial compressive stresses exist before any mechanical loading is applied and these stresses are a source of extra strength for the matrix. The residual stresses are included in all calculations herein of the critical matrix cracking stress and the ultimate strength.

\section{Steady-State Matrix Cracking Stress}

Two distinctive failure modes for steady-state condition that were observed in the experiments are considered: (1) single matrix fracture for a strong interface (perfectly bonded case), and (2) multiple matrix fracture for a weak interface (slipping fibers case). For single matrix fracture to occur, the SiC/RBSN composite was fabricated at a temperature of $1350{ }^{\circ} \mathrm{C}$, instead of $1200{ }^{\circ} \mathrm{C}$, in $\mathrm{N}_{2}+4 \% \mathrm{H}_{2}$ for $72 \mathrm{hr}$. These processing conditions degrade the usual double carbon-rich coating of the fiber and destroy the weak interface between them. A model that predicts the steady-state matrix cracking stress for single matrix fracture, was first proposed by Aveston and Kelly (1973) and later refined by Budiansky et al. (1986) using fracture mechanics theory, giving the following relations 


$$
\sigma_{s s}^{s}=B\left[\frac{6 E_{c}^{3} f^{2} E_{f}}{(1-f)^{2}\left(1+\nu_{m}\right)}\right]^{\frac{1}{4}}\left[\frac{G_{m}}{E_{m} R}\right]^{\frac{1}{2}}
$$

where

$$
B=\left[\frac{2(1-f)^{3}}{-\epsilon \ln (f)-3(1-f)(3-f)}\right]^{\frac{1}{4}}
$$

Since the radial residual stress has no effect for the perfectly bonded case, the critical matrix cracking strength becomes

$$
\sigma_{c r}=\sigma_{s s}^{s}-\sigma_{m}^{\prime} \mathrm{E}_{c} / \mathrm{E}_{\mathrm{m}}
$$

The effects on $\sigma_{c r}$ of $G_{m}, f, R$ and the difference in $\alpha_{f}$ and $\alpha_{m}$ are presented in figure 17. For a selected fiber content of 28 percent and Poisson's ratio of 0.22 , the critical matrix cracking stress varies little with $G_{m}$. If the difference in CTE increased for $\alpha_{f}>\alpha_{m}$, the critical matrix cracking stress would rise significantly. In figure $17(\mathrm{~d})$, it is clear that $\sigma_{\mathrm{cr}}$ is maximum for small fiber diameters. As anticipated, the model predicts that increasing the fiber content would also enhance $\sigma_{\mathrm{cr}}$. Since it was impossible to accurately measure the critical matrix cracking stress experimentally, the ultimate strength of specimen S1B was used to compare the prediction of the model at 8-percent fiber content. The measured experimental value was slightly higher than the expected strength from theory

(fig. $17(\mathrm{~b}))$. Note that $\sigma_{\mathbf{g s}}^{\mathbf{s}}$ in equation (7) is independent of the interfacial shear strength.

The desired failure mode for SiC/RBSN composites is multiple matrix fracture which exploits the high fiber properties and provides graceful failure for the laminate. Micromechanical models to predict the matrix cracking stress for weak interface conditions have been proposed by a number of researchers using different methodologies. An early model, originally proposed by Aveston et al. (1971) is based on the energy-balance approach, and is derived herein using fracture mechanics theory and the assumption of intact bridging fibers (Marshall and Cox, 1988). Based on the J-integral method, the relation for steady-state matrix cracking is

$$
\mathrm{J}_{\mathrm{c}} / 2=\sigma_{\mathrm{a}} \mathrm{u}_{\mathrm{a}}-\int_{0}^{\mathrm{u}_{\mathrm{a}}} \mathrm{p}(\mathrm{u}) \mathrm{du}
$$

where $2 \mathrm{u}_{\mathrm{a}}$ is the critical crack opening corresponding to the applied stress, $\sigma_{\mathbf{a}}$. If there is no ligament failure accompanying crack propagation, then the fracture criterion for matrix cracking is

$$
\mathrm{J}_{\mathrm{c}}=(1-\mathrm{f}) \mathrm{G}_{\mathrm{m}}
$$

The crack closing pressure, $p(u)$, arising from the bridging fibers can be calculated from (McCartney, 1987) 


$$
p(u)=\left[\frac{4 \tau f^{2} E_{f} E_{c}^{2}}{R(1-f)^{2} E_{m}^{2}}\right]^{\frac{1}{2}} u^{\frac{1}{2}}
$$

By substituting equations (11) and (12) into (10) and setting $\sigma_{a}=p\left(u_{a}\right)$, the steady-state matrix cracking stress for multiple matrix fracture becomes

$$
\sigma_{s s}^{M}=\left[\frac{6 \tau G_{m} f^{2} E_{f} E_{c}^{2}}{R(1-f) E_{m}^{2}}\right]^{1 / 3}
$$

Therefore, the expression for predicting the critical matrix cracking strength with residual stress effects is

$$
\sigma_{c r}=\sigma_{\mathbf{s} \mathbf{s}}^{M}\left(\tau+\tau_{\mathbf{R}}\right)-\sigma_{\mathrm{m}}^{\prime} \mathrm{E}_{\mathrm{c}} / \mathrm{E}_{\mathrm{m}}
$$

where $\quad \sigma_{\mathbf{s}}^{M}$ is a function of an effective interfacial shear strength, that is $\tau_{\mathbf{e}}=\tau+\tau_{\mathbf{R}}$.

Parametric calculations using equation (14) were made for the SiC/RBSN composite ith 28-percent fiber content, interfacial frictional strength, $\tau$, of $10 \mathrm{MPa}$, and $\mu$ equal to 0.1 . The results are plotted in figure 18 showing the effects of residual stresses and interfacial shear strength. With the strain mismatch producing an initial matrix compressive stress, the composite critical matrix cracking strength is obviously improved. Clearly, the residual stresses can not be neglected even though they may decrease significantly as the operating temperature increases. Equation (13) is valid only up to a certain value of $\tau$ that assures multiple transverse matrix cracking, and the maximum $\tau$ used herein for this failure mode was $45 \mathrm{MPa}$. This value is based on the maximum value of $\tau$ that can be successfully measured from the push-out test in our laboratory. In figure 19(a), the critical matrix cracking strength is plotted as a function of fiber radius using equations (2), (3), (13) and (14). As mentioned before, small radius fibers will enhance the microcrack yield strength of unidirectional CMC's. However, improving matrix fracture toughness will not have a significant effect on the matrix cracking strength (fig. 19(b)). Figure 19(c) shows an almost linear relation between $\sigma$ cr and the fiber content. Figure 19(d) shows that higher strain mismatch improves the critical matrix cracking strength, at least when loaded in the fiber direction. The tradeoff is that as the strain mismatch increases, the radial residual stress would cause higher tension in the interface. This would weaken the interfacial shear strength, decrease $\sigma_{\mathbf{s} \mathbf{M}}^{\mathrm{M}}$, and induce interface debonding.

\section{U1timate Strength}

The ultimate strength, which is reached after multiple matrix cracking, was calculated from the strength of initially strong fibers, that were degraded during 
composite fabrication. This was evident when in-situ fibers broke sequentially at unexpectedly low loads rather than simultaneously at higher loads before reaching the ultimate point. This was observed experimentally and has been previously discussed herein. X-radiographic results precisely showed the locations of fiber fracture and the statistical nature of fiber failure in weak interface composites. Therefore, the micromechanical model used to predict the ultimate strength of composites must be based on a statistical distribution. Using weakest link statistics, a recent model (Evans, 1989) is applied which in terms of the fiber Weibull modulus, m, is

$$
\sigma_{u}=f S_{u} \exp \left\{-\frac{\left[1-\left(1-\frac{\mathcal{T x}}{\mathrm{RS}_{\mathrm{u}}}\right)^{\mathrm{n}+1}\right]}{(\mathrm{m}+1)\left[1-\left(1-\frac{\tau \mathrm{x}}{\mathrm{RS}_{\mathrm{u}}}\right)^{\mathrm{m}}\right]}\right\}
$$

with

$$
\begin{aligned}
\left(\frac{\mathrm{RS}_{\mathrm{u}}}{\tau \mathrm{x}}\right)^{\mathrm{n}+1} & =\left(\frac{\mathrm{A}_{\mathrm{o}}}{2 \pi \mathrm{RL}}\right)\left(\frac{\mathrm{RS}_{\mathrm{o}}}{\tau_{\mathrm{X}}}\right)^{\mathrm{m}}\left[1-\left(1-\frac{\tau \mathrm{x}}{\mathrm{RS}_{\mathrm{u}}}\right)^{\mathrm{m}}\right]^{-1} \\
\mathrm{~S}_{\circ} & =\frac{\overline{\mathrm{S}}}{\Gamma\left(1+\frac{1}{\mathrm{~m}}\right)}(2 \pi \mathrm{RH})^{1 / \mathrm{m}}
\end{aligned}
$$

where $\mathrm{L}$ is the gauge length of the composite test specimen, $\mathrm{A}_{O}$ is an area normalizing factor, $S_{O}$ is the scale parameter, $S$ is the average fiber strength, $H$ is the fiber gauge length, $\Gamma$ is the gamma function, $S_{u}$ is determined from equation (16), and $\mathbf{x}$ is the matrix crack spacing obtained from equation (1) as

$$
\mathbf{x}=1.337 R(1-f) \mathrm{E}_{\mathbf{m}} \sigma_{\mathbf{s} \mathbf{s}}^{\mathrm{M}} /\left(2 \mathrm{fE}_{\mathrm{c}} \tau\right)
$$

Using the SiC/RBSN composite properties, an average fiber strength of $2.86 \mathrm{GPa}$, and selected values of $A_{O}, H$ and $L$ as $1 \mathrm{~m}^{2}, 0.025$ and $0.1016 \mathrm{~m}$ respectively, the ultimate strength as a function of Weibull modulus was calculated and the results are shown in figure 20. Clearly, the ultimate strength varies rapidly when $m<20$, that is when the variation in fiber strength is high. The experimental value of the Weibul1 parameter, m, for the SCS-6 SiC fiber was evaluated from uniaxial fiber tension tests performed on finite length specimens of $25 \mathrm{~mm}$ and was estimated to be 8.2 (Bhatt and Phillips, 1988). However, the Weibull modulus of in-situ fibers could be considerably different from those measured independently, since the fiber flaws are expected to change during composite processing. Equation (15) also shows that $\tau$ has very small effect on composite ultimate strength. An approximate check of the composite ultimate strength is often made from using the rule of mixtures, but in case of brittle fibers, the value of in-situ fiber strength to use in the prediction can only be an estimate. 


\section{Work of Pull-out}

Pull-out usually occurs in composites after complete matrix failure with the bridging fibers also containing many random breaks away from the transverse matrix cracks. When interfacial shear strength is low, pull-out lengths are long and the work of pull-out is maximized, providing the composite load carrying capability beyond the ultimate strength. As observed through x-ray results, fibers exhibit variable pull-out lengths after complete failure and the lengths are governed by the Weibull strength distribution parameters. Hence, the work of pull-out must also be expressed in terms of the fiber Weibull modulus and scale parameter.

The work of pull-out had not been given much attention in the past even though Kelly (1970) had demonstrated its significance. Recently, Thouless and Evans (1988) and Sutcu (1989) have investigated the pull-out contribution to the toughness of ceramic matrix composites. In this paper, we will examine a model proposed by Sutcu. For fiber failure caused by a single matrix crack, the peak fiber stress is assumed to occur in the plane of the matrix crack and then drop to zero over a sampling length, L. The slope is governed by the interfacial shear stress and the fiber radius resulting in an expression for $\sigma(z)$ given by (fig. 21)

$$
\sigma(z)=2 \tau(L-z) / R
$$

Based on the Weibull probability density function and the assumption of equation (19), it is possible to derive the average pull-out length $\mathrm{L}_{\mathrm{p}}^{\mathbf{s}}$ for a single matrix crack (Sutcu, 1989)

$$
L_{p}^{s}=\frac{\alpha}{2} R^{\frac{m-1}{m+1}}\left(\frac{S_{o}}{\tau}\right)^{\frac{m}{m+1}}
$$

where

$$
\alpha=1.1 \mathrm{~m} /(\mathrm{m}+1)^{2} \quad(2<\mathrm{m}<60)
$$

and $\mathrm{S}_{\mathrm{O}}$ is obtained from equation (17). The energy release per fiber from pul1-out can be obtained by integrating the force caused by $\tau$ over the slipping distance $z$. The resulting expression for the work of pull-out per unit area of the composite for a single crack is

$$
W_{P}^{s}=\frac{\beta}{4} f R^{\frac{m-3}{m+1}} \frac{S_{0}^{\frac{2 m}{m+1}}}{\tau^{\frac{m-1}{m+1}}}
$$

where

$$
\beta(m)=\frac{2.14(m-1)}{m^{2}(m+2)}[1-\exp (-0.387 m)]
$$


For fiber failure with multiple matrix cracking, the stress in the fibers is assumed to be of a sawtooth form as shown in figure 22 with the peak stress, $\sigma_{\max }$, given by

$$
\sigma_{\max }=2 \tau \mathrm{L} / \mathrm{R}
$$

However, for simplicity a uniform stress profile was used by Sutcu (1989) to derive the following results. The average pull-out length for multiple matrix cracking,

$$
\mathrm{L}_{\mathrm{p}}^{\mathrm{M}} \text {, is given by }
$$

$$
L_{p}^{M}=\frac{a^{\prime}}{2} R^{\frac{m-1}{m+1}}\left(\frac{S_{o}}{\tau}\right)^{\frac{m}{m+1}}
$$

where

$$
\frac{a^{\prime}}{\alpha}=\frac{(m+1)^{\frac{m}{m+1}}}{2}
$$

Finally, the work of pull-out for multiple matrix cracking is similar to the case of single matrix cracking and is defined by

$$
W_{p}^{M}=W_{p}^{\mathcal{s}}\left(\frac{m+2}{6}\right)(m+1)^{\frac{m-1}{m+1}}
$$

Note that the assumption of a uniform, rather than periodic, stress distribution leads to a larger pull-out length and subsequent work of pull-out. Hence these results must be regarded as upper bounds.

The work of pull-out for both single and multiple matrix cracking increases with average fiber strength and fiber radius, but decreases with increasing values of $\tau$. Similar trends can be observed in the average fiber pull-out lengths. The work of pull-out for single matrix cracking is plotted in figure 23 as a function of the Weibull modulus. It shows that the fibers should have a low Weibull modulus to enhance fiber pull-out beyond the ultimate strength. Furthermore, the work of pul1out approaches zero when the variation of fiber strength decreases which is what was observed experimentally in composites with brittle failure modes. Figure 24 shows that the work of pull-out for multiple matrix cracking initially increases and then decreases gradually with increasing $m$; it asymptotically approaches a particular value which can be explained as follows. The stresses in the fibers are highest in the matrix cracking planes. Therefore, for deterministic fiber strength, the fibers will fail at different matrix crack surfaces, not necessarily at the same crack. In this case the broken fibers can still bridge the cracks and eventually produce the work of pull-out. 


\section{Numerical Example}

An example is given below for comparison of predicted and measured stressstrain curves for specimen M8A. It should be noted that the micromechanical models herein assume that no fiber breakage and matrix cracking occur before reaching the critical matrix cracking strength, while actual test specimens showed some fiber fracture and matrix cracking before the proportional limit strength was reached. The nominal values of parameters used in the prediction are:

$$
\begin{aligned}
\mathrm{m} & =8.2 \\
\mathrm{E}_{\mathrm{m}} & =110 \mathrm{GPa} \\
\mathrm{E}_{\mathrm{f}} & =390 \mathrm{GPa} \\
\nu_{\mathrm{m}} & =0.22 \\
\mathrm{~K}_{\mathrm{m}} & =2 \mathrm{MPam} \\
\mathrm{G}_{\mathrm{m}} & =36 \mathrm{~J} / \mathrm{m}^{2} \\
\mathrm{R} & =71 \mu \mathrm{m} \\
\mathrm{f} & =0.24 \\
\alpha_{f} & =4.2 \mathrm{E}-6 /{ }^{\circ} \mathrm{C} \\
\alpha_{\mathrm{m}} & =3.8 \mathrm{E}-6 /{ }^{\circ} \mathrm{C} \\
\Delta \mathrm{T} & =-1175^{\circ} \mathrm{C} \\
\mathrm{A}_{\mathrm{O}} & =1 \mathrm{~m}^{2} \\
\mathrm{~S} & =2860 \mathrm{MPa} \\
\mathrm{L} & =0.04 \mathrm{~m}
\end{aligned}
$$

The interfacial shear strength used was $5 \mathrm{MPa}$ based on the matrix crack spacing method. This value includes the effect of the radial residual stress. Hence, the critical matrix cracking strength was calculated from equations (3), (13) and (14). The ultimate strength and work of pull-out were determined from equations (15) and (27), respectively. Results are plotted in figure 25 together with the experimental stress-strain curve. For the critical matrix cracking strength, the value of $155 \mathrm{MPa}$ is calculated and compared with the measured value of $195 \mathrm{MPa}$ which is taken as the proportional limit stress. Ignoring early damage, the prediction is conservative and it also requires precise knowledge of the in-situ material constituent properties, especially $\tau$. However, caution should be exercised when one defines the critical matrix cracking strength from macroscopic experiments since some irreversible damage occurs earlier which is not evident from the linear portion of the stress-strain curves. The predicted ultimate strength is $492 \mathrm{MPa}$, which is 15-percent lower than the experimental estimate (table I). For the work of pull-out, the experimental result shows a very small value of $42 \mathrm{~kJ} / \mathrm{m}^{2}$ which is significantly less than the predicted result of $2158 \mathrm{~kJ} / \mathrm{m}^{2}$. The source of this discrepancy is mainly due to interfacial debonding (splitting) that occurred extensively in the 8-ply sample and, consequently, the modeled pull-out phenomenon was never realized in the test. Furthermore, as previously noted, the predicted value is an upper bound solution. 


\section{CONCLUDING REMARKS}

Failure mechanisms in unidirectional fiber-reinforced SiC/RBSN ceramic matrix composites under tension have been investigated. It is possible to detect damage accumulation and various failure processes while loading the specimens via in-situ acoustic emission monitoring and $x$-radiography. Tests of samples with various fiber fractions show that the transition from catastrophic to noncatastrophic failure occurs at approximately 16- to 19-percent fiber content. Based only on stress-strain curves and $x$-ray results, there was no indication of any failure event before catastrophic failure when low fiber content specimens were tested. However, acoustic emission results indicate that some fiber breakage, transverse matrix cracking and some fiber/matrix interface debonding had occurred long before catastrophic fracture. Similar phenomena took place in the noncatastrophically failed samples during the linear portion of their stress-strain curves. The macroscopic effect of this early (microscopic) damage on overall composite design philosophy and behavior requires additional studies and investigation. The interfacial shear strengths of the selected $\mathrm{SiC} / \mathrm{RBSN}$ composites measured by the push-out test and the matrix crack spacing method were low. For this case, extensive interface debonding or splitting occurs and causes a reduction in the work of pull-out. This debonding or axial splitting is very undesirable. To obtain composites with high strength and toughness, the interfacial shear strength should be high enough to prevent interface debonding but low enough to allow steady-state cracking and substantial fiber pullout lengths for graceful failure. Micromechanical models incorporating residual stresses to predict the critical matrix cracking strength, ultimate strength and work of pull-out were used and the predictions were compared to measured values. The fiber Weibull modulus is an important parameter for both the ultimate strength and the work of pull-out. When variation in fiber strength is low, the ultimate strength is high. Conversely, when the variation is high, the work of pull-out is also high. By comparing predictions from these models with experiments, we can conclude that they are valid only if steady-state conditions occur and fiber breakage is minimized, at least for loads below the critical matrix cracking condition. For these reasons, only 2 specimens were used to validate these models since the other specimens did not show the required steady state response. Accurate knowledge of in-situ material constituent properties is also equally important. Based on parametric studies and experimental observations, the optimum SiC/RBSN composite should meet the following requirements: fiber content as high as permitted by processing considerations (above 30 percent), fiber radius for optimum critical matrix cracking strength (below $35 \mu \mathrm{m})$, slightly higher fiber CTE than that of the matrix, an optimum fiber Weibull modulus for ultimate strength and work of pull-out (between 8 and 20), and the optimum ratio of interfacial shear strength divided by the fiber radius for high multiple matrix cracking strength and adequate pull-out toughness depending on design considerations and applications.

\section{REFERENCES}

Aveston, J., Cooper, G.A., and Kelly, A., 1971, "Single and Multiple Fracture, in The Properties of Fibre Composites," Conference Prodeedings, National Physical Laboratory, Guildford. IPC Science and Technology Press Ltd, Surrey, England, pp. 15-26.

Aveston, J. and Kelly, A., 1973, "Theory of Multiple Fracture of Fibrous Composites," Journal of Materials Science, Vol. 8, pp. 352-362. 
Baaklini, G.Y., and Bhatt, R.T., 1991, "X-Ray Monitoring of Damage Accumulation in SiC/RBSN Tensile Specimens," to appear in Ceramic Engineering and Science Proceedings, 15th Annual Conference on Composites and Advanced Ceramic Materials, Cocoa Beach, F1, Jan. 13-16.

Bhatt, R.T., 1987, "Method of Preparing Fiber-Reinforced Ceramic Materials," U.S. Patent No. 4689188.

Bhatt, R.T., 1989, unpublished report.

Bhatt, R.T., and Kiser, J.D., 1990, "Matrix Density Effects on the Mechanical Properties of SiC/RBSN Composites," NASA TM-103098.

Bhatt, R.T. and Phillips, R.E., 1988, "Laminate Behavior for SiC Fiber-Reinforced Reaction-Bonded Silicon Nitride Matrix Composites," NASA TM-101350.

Brennan, J.J., and Prewo, K.M., 1982, "Silicon Carbide Fiber-Reinforced Glass-Ceramic Matrix Composites Exhibiting High Strength and Toughness," Journal of Materials Science, Vol. $17(8)$, pp. 2371-2383.

Budiansky, B., Hutchinson, J.W., and Evans, A.G., 1986, "Matrix Fracture in Fiberreinforced Ceramics," Journal of the Mechanics and Physics of Solids, Vol. 34, pp. 167-189.

Chulya, A., Baaklini, G.Y., and Bhatt, R.T., 1990, "Characterization of Damage and Fracture Mechanisms in Continuous Fiber-Reinforced SiC/RBSN Ceramic Matrix Composites by Acoustic Emission," NASA CP-10051, The 3rd Annual HITEMP Review Proceedings, pp. 55-1 to 55-15.

DiCarlo, J.A., and Williams, W., 1980, "Dynamic Modulus and Damping of Boron, Silicon Carbide, and Alumina Fibers," NASA TM-81422.

Eldridge, J.I., and Honecy, F.S., 1990, "Characterization of Interfacial Failure in $\mathrm{SiC}$ Reinforced $\mathrm{Si}_{3} \mathrm{~N}_{4}$ Matrix Composite Material by Both Fiber Push-out Testing and Auger Electron Spectroscopy," Journal of Vacuum Science and Technology. Series A, Vo1. 8, May-June, pp. 2101-2106.

Evans, A.G., 1989, "The Mechanical Performance of Fiber-reinforced Ceramic Matrix Composites," Materials Science and Engineering, A107, pp. 227-239.

Haggerty, J.S., 1989, "Ceramic-Ceramic Composites with Reaction Bonded Matrices," Materials Science and Engineering, A107, pp. 117-125.

He, M. and Hutchinson, J.W., 1989, "Crack Deflection at an Interface Between Dissimilar Elastic Materials," International Journal of Solids and Structures, Vol. 25(9), pp. 1053-1067.

Ke11y, A., 1970, "Interface Effects and the Work of Fracture of a Fibrous Composite," Royal Society of London. Proceedings. Series A, Vol. 319, pp. 95-116.

Kerans, R.J., Hay, R.S., Pagano, N.J., and Parthasarathy, T.A., 1989, "The Role of The Fiber-Matrix Interface in Ceramic Composites," The American Ceramic Society Bulletin, Vol. 68(2), pp. 429-442. 
Kimber, A.C. and Keer, J.G., 1987, "On the Theoretical Average Crack Spacing in Brittle Matrix Composites Containing Aligned Fibers," Journal of Materials Science Letters, Vol. 1, pp. 353-354.

Marsha11, D.B., 1984, "An Indentation Method for Measuring Matrix-Fiber Frictional Stresses in Ceramic Composites," Journal of American Ceramic Society, Vol. 67, December, pp. C-259 to C-260.

Marsha11, D.B. and Cox, B.N., 1988, "A J-integral Method for Calculating Steady-state Matrix Cracking Stresses in Composites," Mechanics of Materials, Vo1. 7, pp. 127-133.

Marsha11, D.B., Cox, B.N., and Evans, A.G., 1985, "The Mechanics of Matrix Cracking in Brittle-Matrix Fiber Composites," Acta Metallurgica, Vol. 33(11), pp. 2013-2021.

Marsha11, D.B., and 0liver, W.C., 1987, "Measurement of Interfacial Mechanical Properties in Fiber-Reinforced Ceramic Composites," Journal of American Ceramic Society, Vol. 70 (8), pp. 542-548.

McCartney, L.N., 1987, "Mechanics of Matrix Cracking in Brittle-Matrix FiberReinforced Composites," Royal Society of London. Proceedings. Series A, Vol. 409, pp. 329-350.

Moschler, J.W., 1988, "Investigation of Failure Modes in Fiber Reinforced Ceramic Matrix Composites," MS Thesis, Air Force Institute of Technology, Wright-Patterson $\mathrm{AFB}, \mathrm{OH}$, December.

Prewo, K.M., 1986, "Tension and Flexural Strength of Silicon Carbide Fiber-Reinforced Glass-Ceramics," Journal of Materials Science, Vol. 21, pp. 3590-3600.

Prewo, K.M. and Brennan, J.J., 1980, "High-Strength Silicon Carbide Fiber-Reinforced Glass-Matrix Composites," Journal of Materials Science, Vol. 15(2), pp. 463-468.

Prewo, K.M. and Brennan, J.J., 1982, "Silicon Carbide Yarn Reinforced Glass Matrix Composites," Journal of Materials Science, Vol. 17(4), pp. 1202-1206.

Sutcu, M., 1989, "Weibull Statistics Applied to Fiber Fracture in Ceramic Composites and Work of Fracture," Acta Metallurgica, Vol. 37(2), pp. 651-661.

Thouless, M.D. and Evans, A.G., 1988, "Effects of Pull-out on the Mechanical Properties of Ceramic-matrix Composites," Acta Metallurgica, Vol. 36(3), pp. 517-522. 
TABLE I. - ROOM TEMPERATURE MECHANICAL PROPERTY DATA FOR UNIDIRECTIONAL SiC/RBSN

\begin{tabular}{|c|c|c|c|c|c|c|c|c|}
\hline & & & & APUSIT & & & & \\
\hline \multirow{2}{*}{$\begin{array}{l}\text { Specimen } \\
\text { identi- } \\
\text { fication }\end{array}$} & \multirow{2}{*}{$\begin{array}{c}\text { Number } \\
\text { of } \\
\text { plies }\end{array}$} & \multirow{2}{*}{$\begin{array}{c}\text { Interface } \\
\text { charac- } \\
\text { teristic }\end{array}$} & \multirow{2}{*}{$\begin{array}{l}\text { Fiber } \\
\text { ratio, } \\
\text { percent }\end{array}$} & \multicolumn{2}{|c|}{ Primary modulus } & \multicolumn{2}{|c|}{$\begin{array}{c}\text { Proportional } \\
\text { limit }\end{array}$} & \multirow{2}{*}{$\begin{array}{l}\text { Ultimate } \\
\text { strength, } \\
\mathrm{MPa}^{-}\end{array}$} \\
\hline & & & & $\begin{array}{c}\text { Experi- } \\
\text { ment, } \\
\mathrm{GPa}\end{array}$ & $\begin{array}{c}\mathrm{ROM},{ }^{\mathrm{a}} \\
\mathrm{GPa}\end{array}$ & $\begin{array}{c}\text { Stress, } \\
\mathrm{MPa}\end{array}$ & $\begin{array}{l}\text { Strain, } \\
\text { percent }\end{array}$ & \\
\hline $\mathrm{S} 1 \mathrm{~A}$ & 1 & Weak & 8 & 149 & 132 & 104 & 0.070 & 104 \\
\hline $\mathrm{S} 1 \mathrm{~B}$ & 1 & Strong & 8 & 157 & 132 & 166 & .106 & 166 \\
\hline $\mathrm{M} 3 \mathrm{~A}$ & 3 & Weak & 16 & 178 & 155 & 178 & .100 & 178 \\
\hline $\mathrm{M} 5 \mathrm{~A}$ & 5 & Weak & 19 & 171 & 163 & 186 & .108 & 222 \\
\hline M5B & 5 & Weak & 19 & 197 & 163 & 226 & .115 & 228 \\
\hline M5C & 5 & Weak & 19 & 171 & 163 & 179 & .105 & 227 \\
\hline $\mathrm{M} 8 \mathrm{~A}$ & 8 & Weak & 24 & 175 & 177 & 195 & .124 & 576 \\
\hline
\end{tabular}

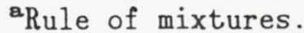

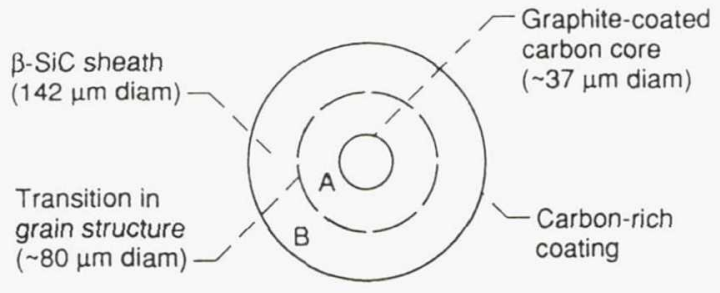

(a) Schematic of cross section of fiber.

Coating composition

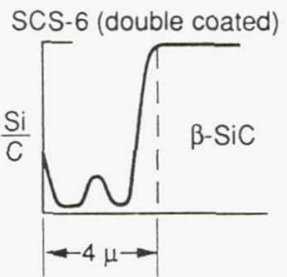

(b) Composition profile of carbon-rich coating on fiber surface (Textron SCS-6).

Figure 1.-Details of CVD SiC fiber.

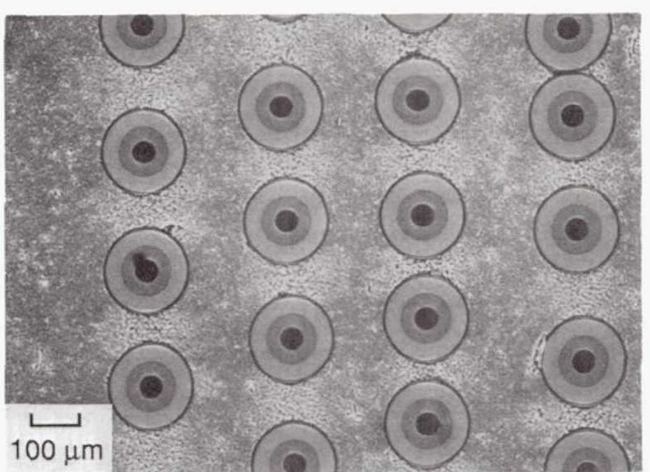

(a) A typical cross-section of a unidirectionally reinforced SiC/RBSN composite.

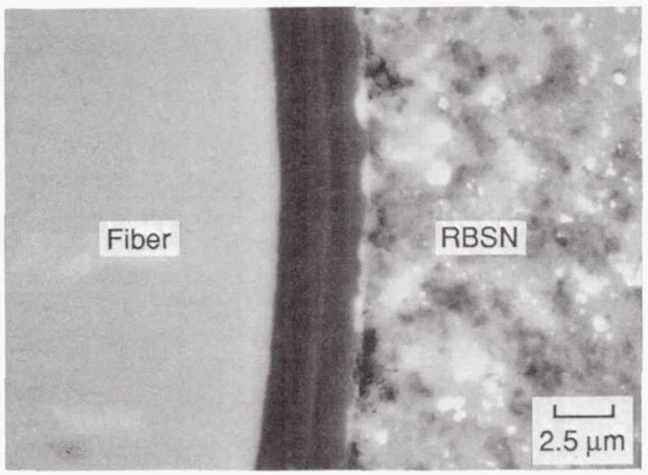

(b) Photomicrograph showing the interfacial region in SiC/RBSN composites.

Figure 2.-Typical cross-section and the interface region of SiC/RBSN composites. 


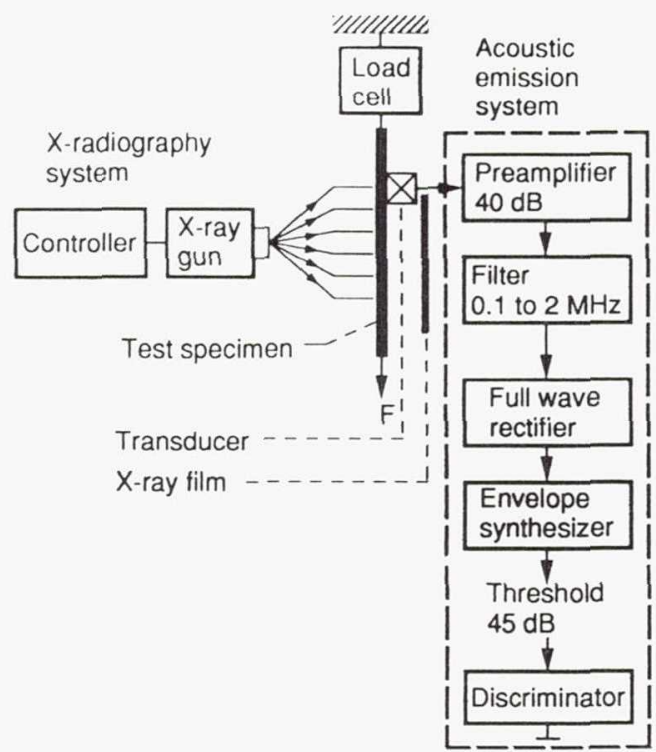

(a) Acoustic emission and $x$-radiography setups on the loadframe.

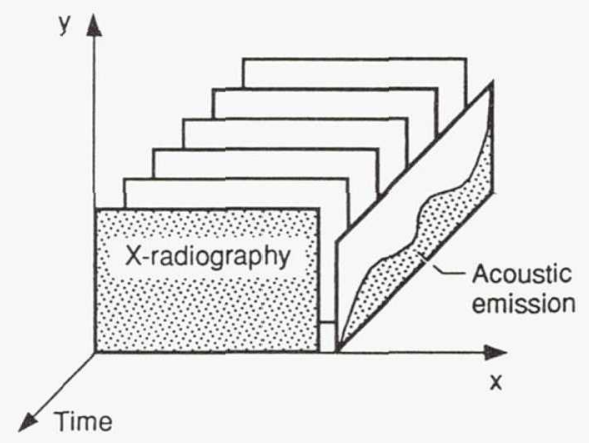

(b) Acoustic emission showing real time dependence.

Figure 3.-Tensile specimen with acoustic emission and $\mathrm{x}$-radiography.

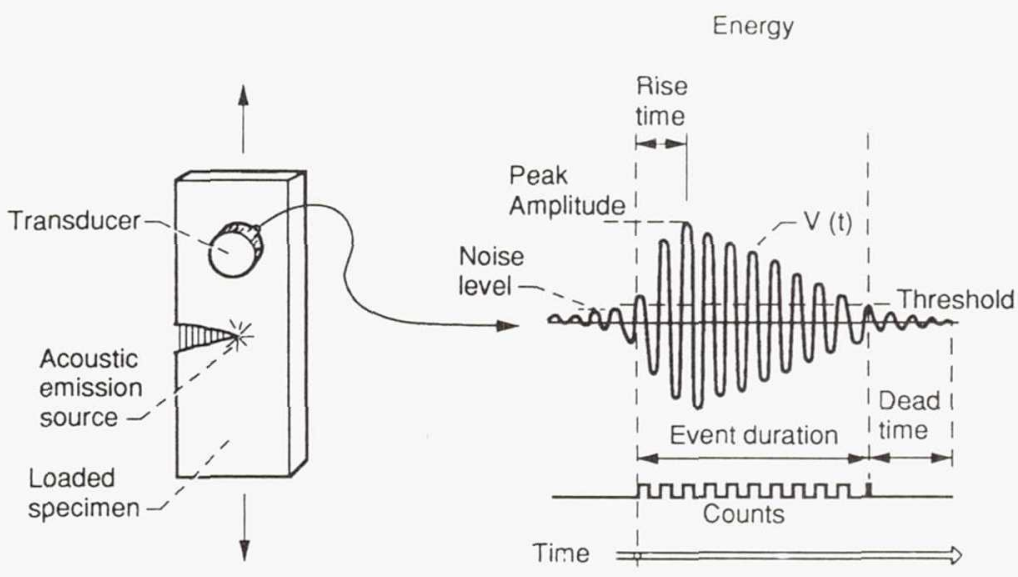

Figure 4.-Definition of an acoustic emission event or hit.

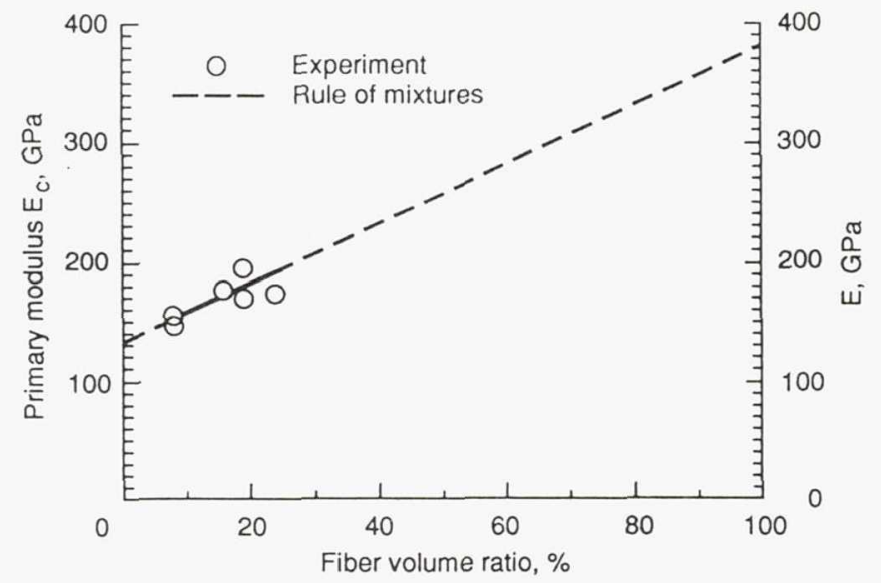

Figure 5.-Primary modulus of SiC/RBSN composite from experiment and the rule of mixtures.
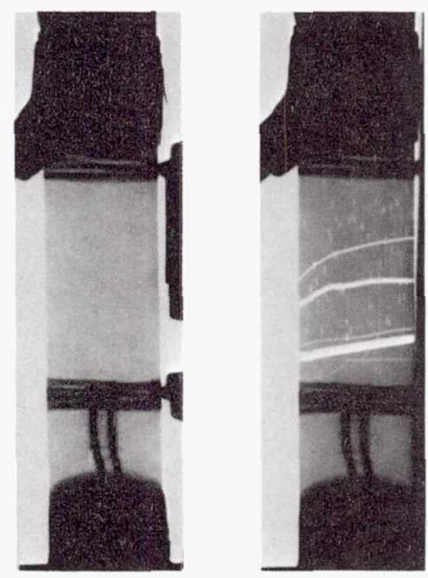

\section{Before failure $(1330 \mathrm{~N})$}

Conventional radiographs

At failure $(1425 \mathrm{~N})$

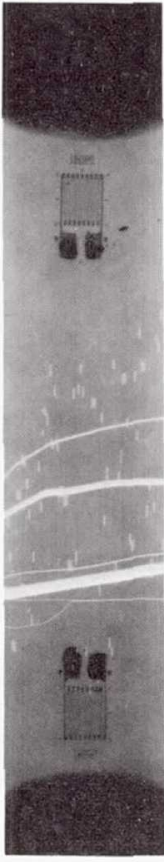

After

failure

Figure 6.-X-radiographic results for specimen S1A. 


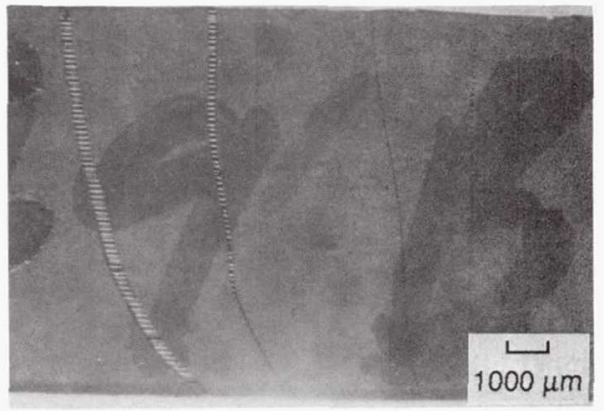

Front

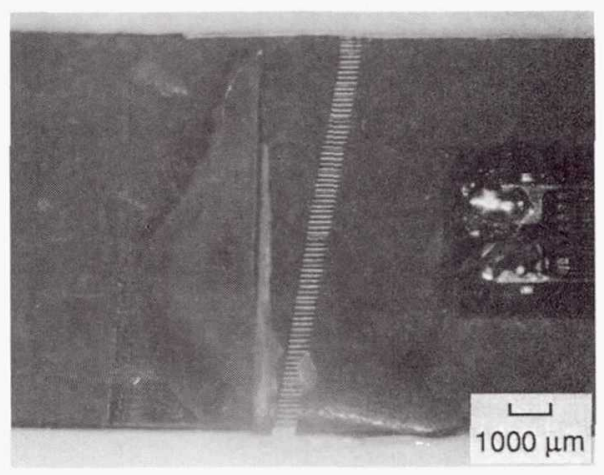

Back

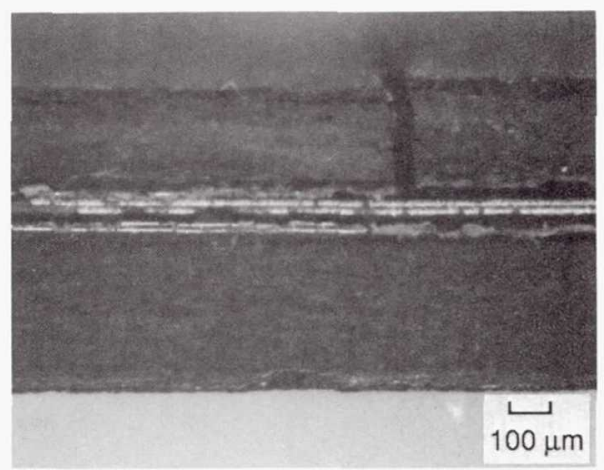

Side

Figure 7.-Optical photomicrographs of matrix cracking and debonding for specimen S1A.

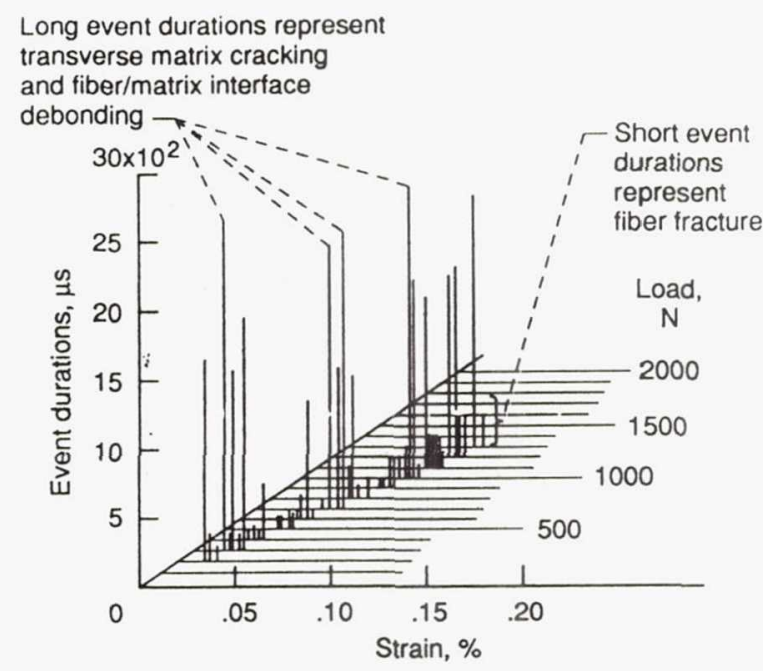

Figure 8.-Three-dimensional plot of event durations, load and strain for specimen S1A. 


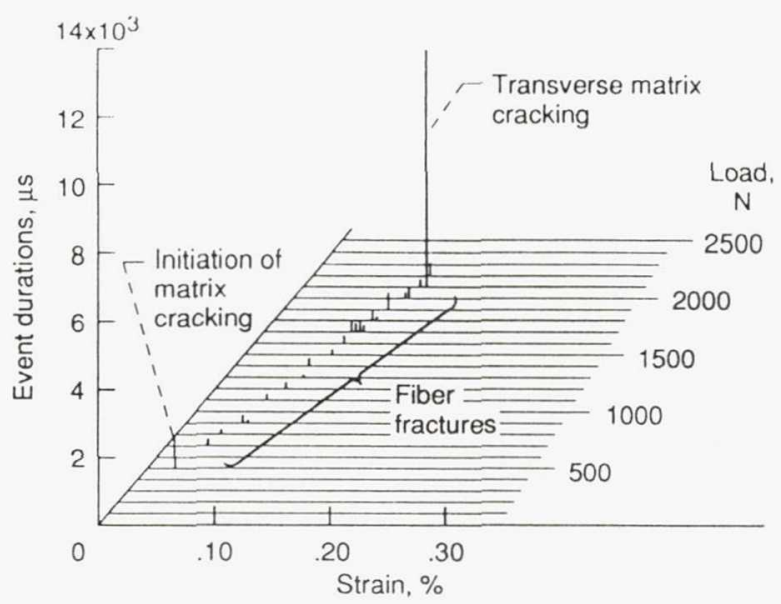

Figure 9.-Three-dimensional plot of event durations, load and strain for specimen S1B.

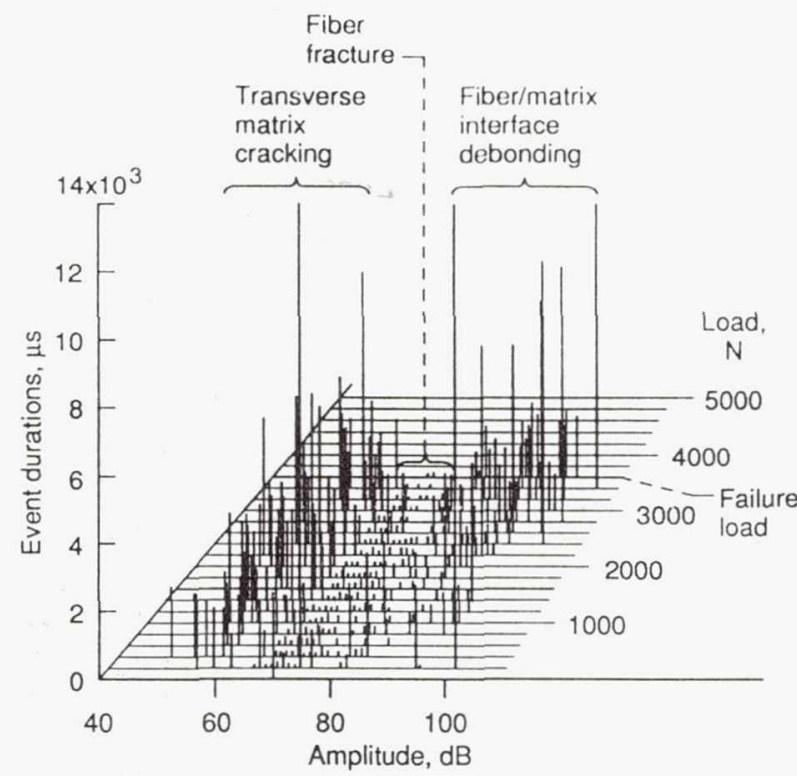

Figure 10.-Three-dimensional plot of event durations, amplitude, and load for specimen M3A.

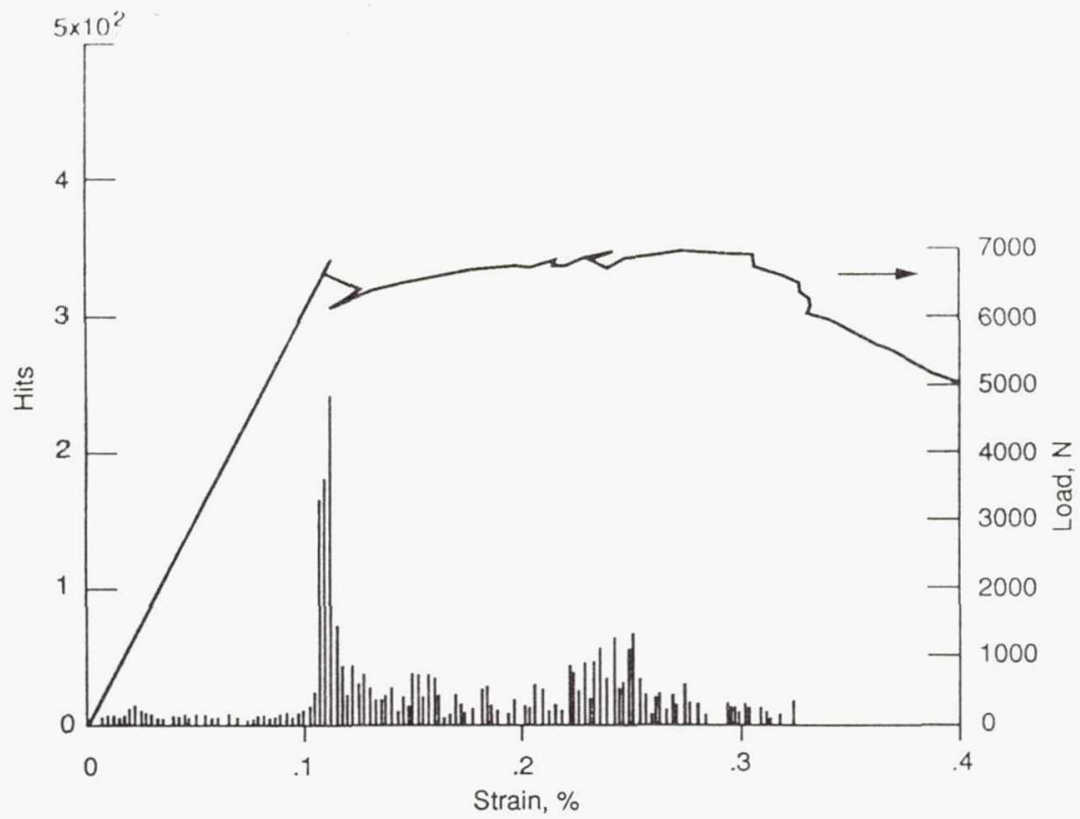

Figure 11. - Load-strain curve with AE hit parameter for specimen M5B. 


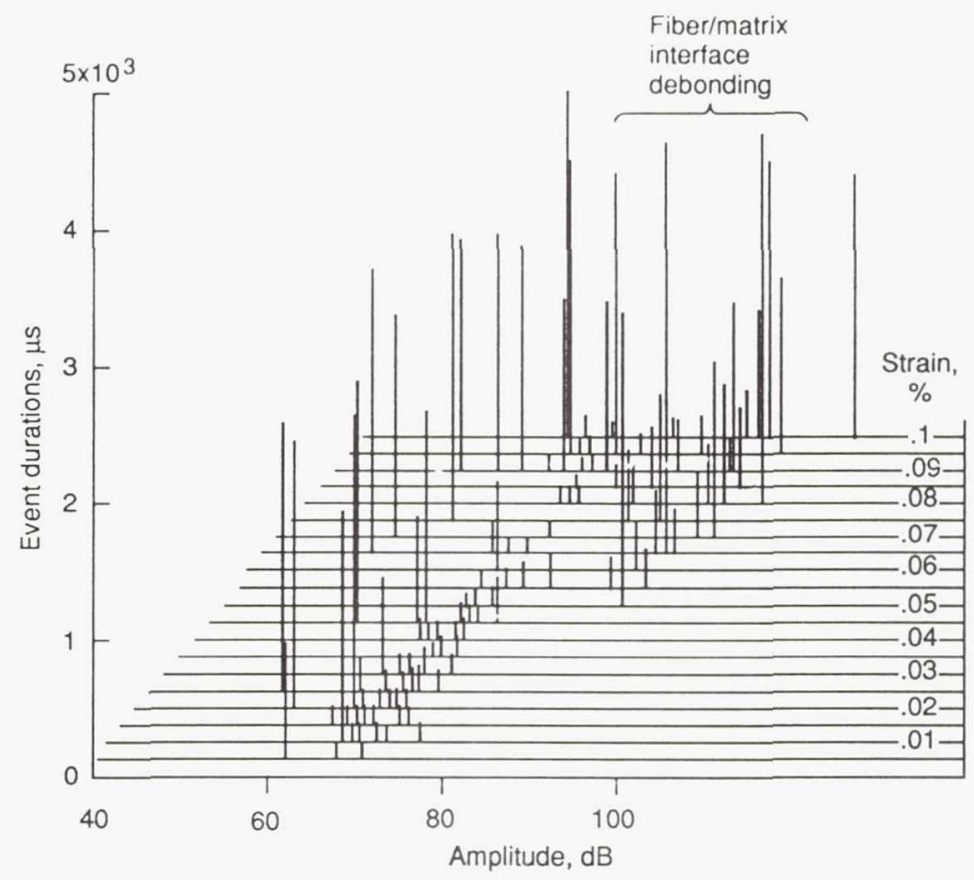

Figure 12.-AE parameter plot in the linear strain regime for specimen M5B.

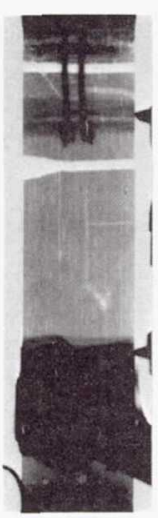

Conventional radiograph after failure

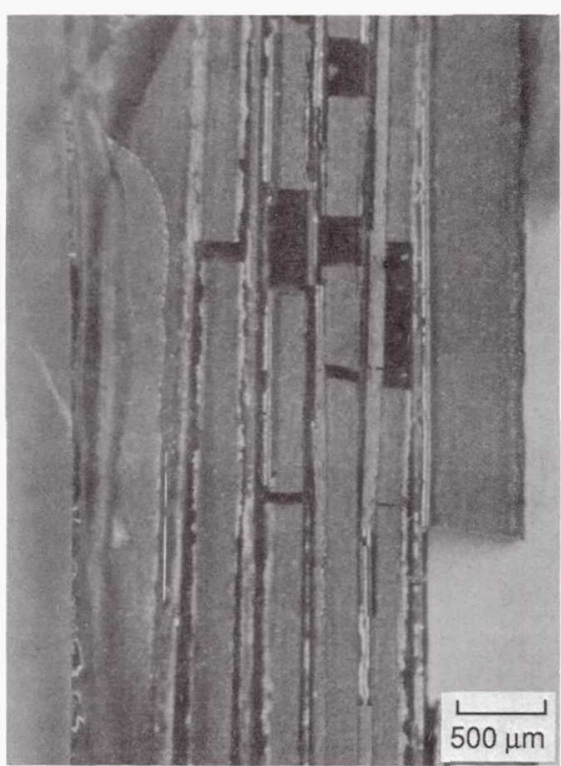

Optical

photomicrograph

Figure 13.-X-ray film and optical photomicrograph at failure for specimen $\mathrm{M} 5 \mathrm{C}$. 


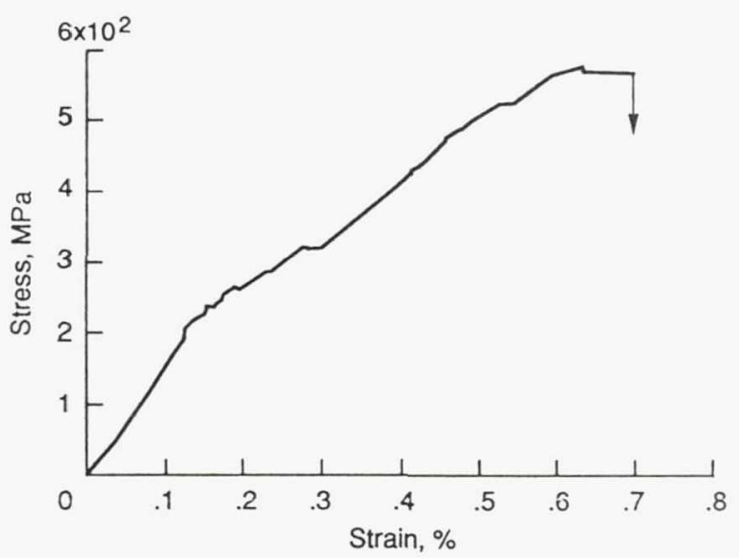

Figure 14.-Stress-strain curve for specimen M8A.

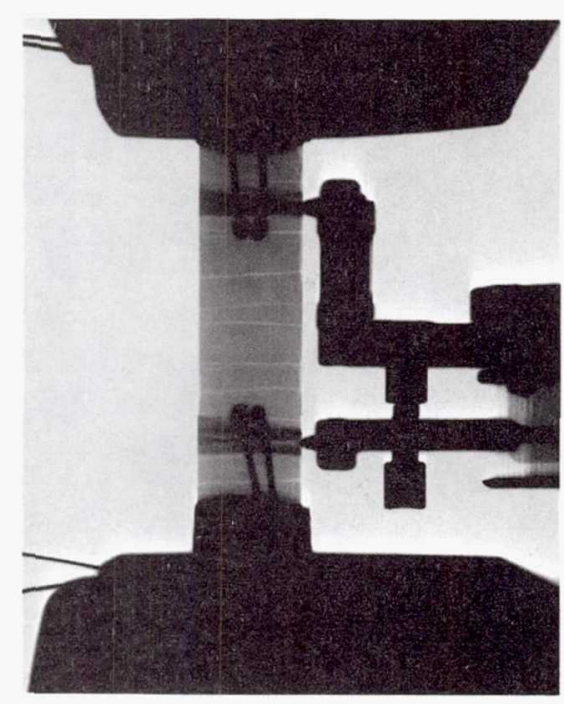

Figure 15.-X-ray film for specimen M8A showing transverse matrix crack spacing.

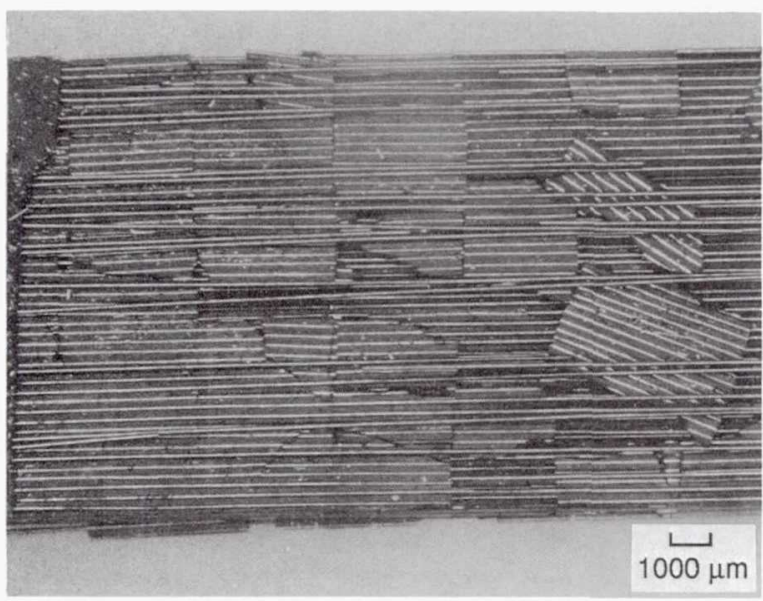

(a) Front.

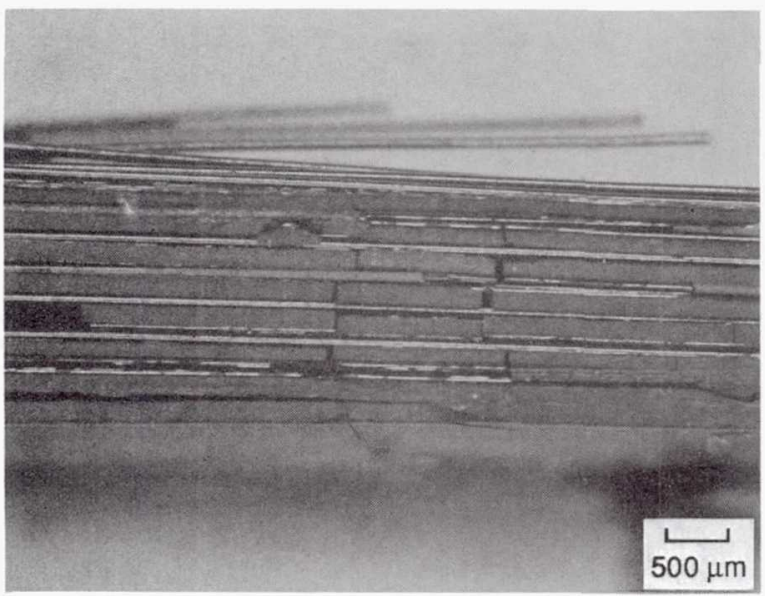

(b) Side.

Figure 16.-Optical photomicrographs of specimen M8A. 

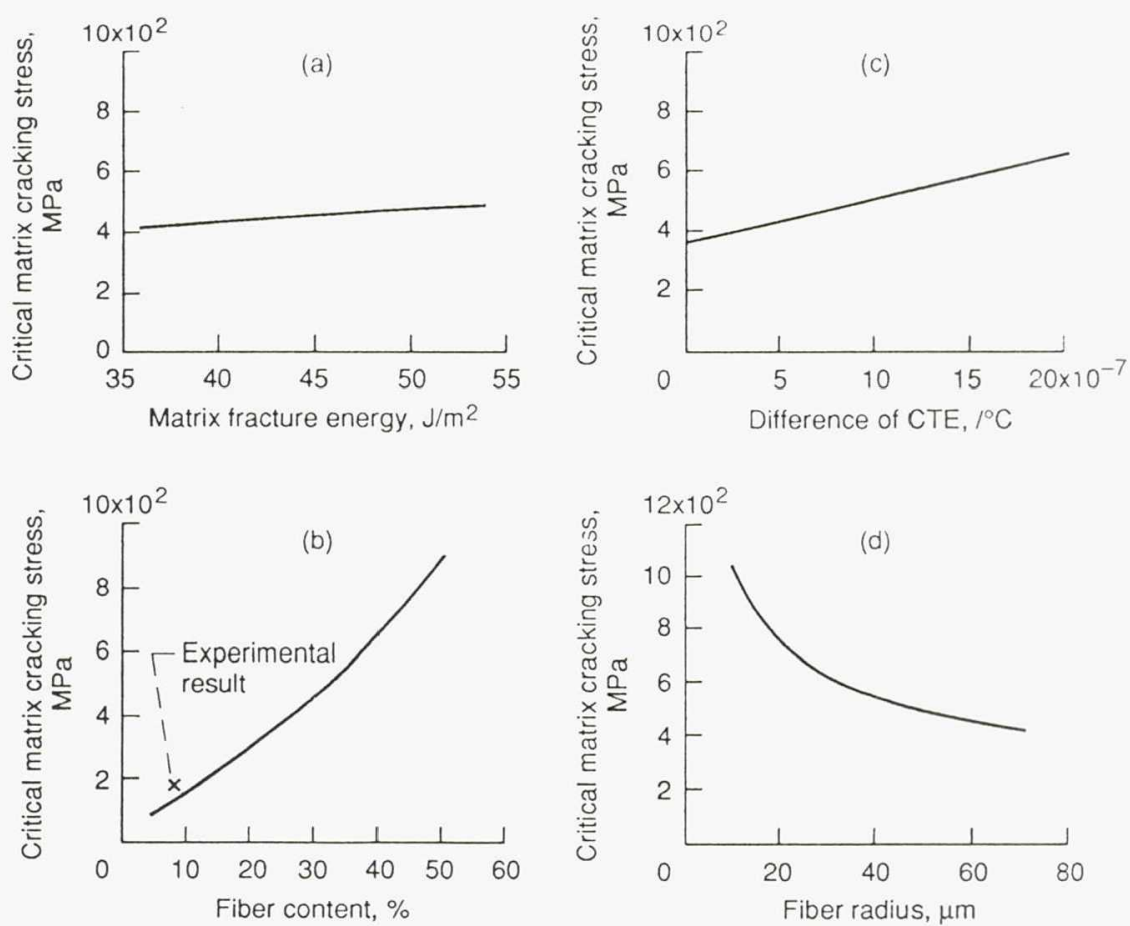

Figure 17.-Parametric studies of critical matrix cracking stress for the perfectly bonded case.

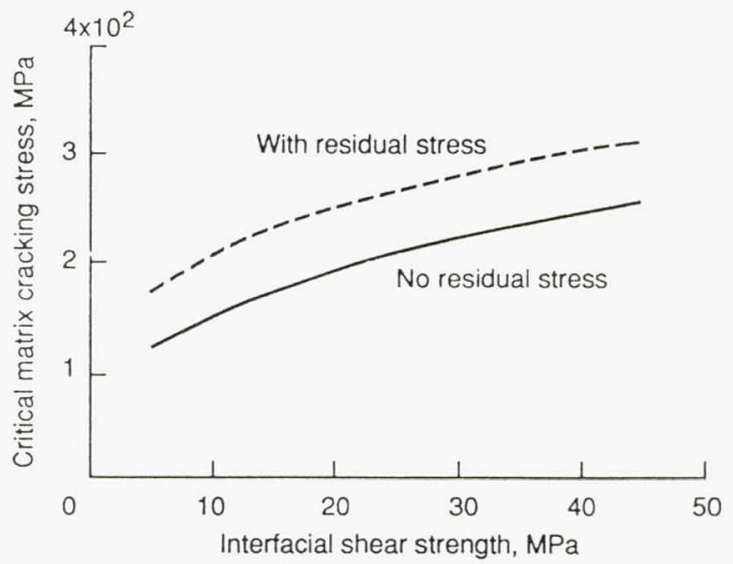

Figure 18.-Variation of critical matrix cracking stress with interfacial shear strength for multiple matrix cracking (slipping fibers) case. 

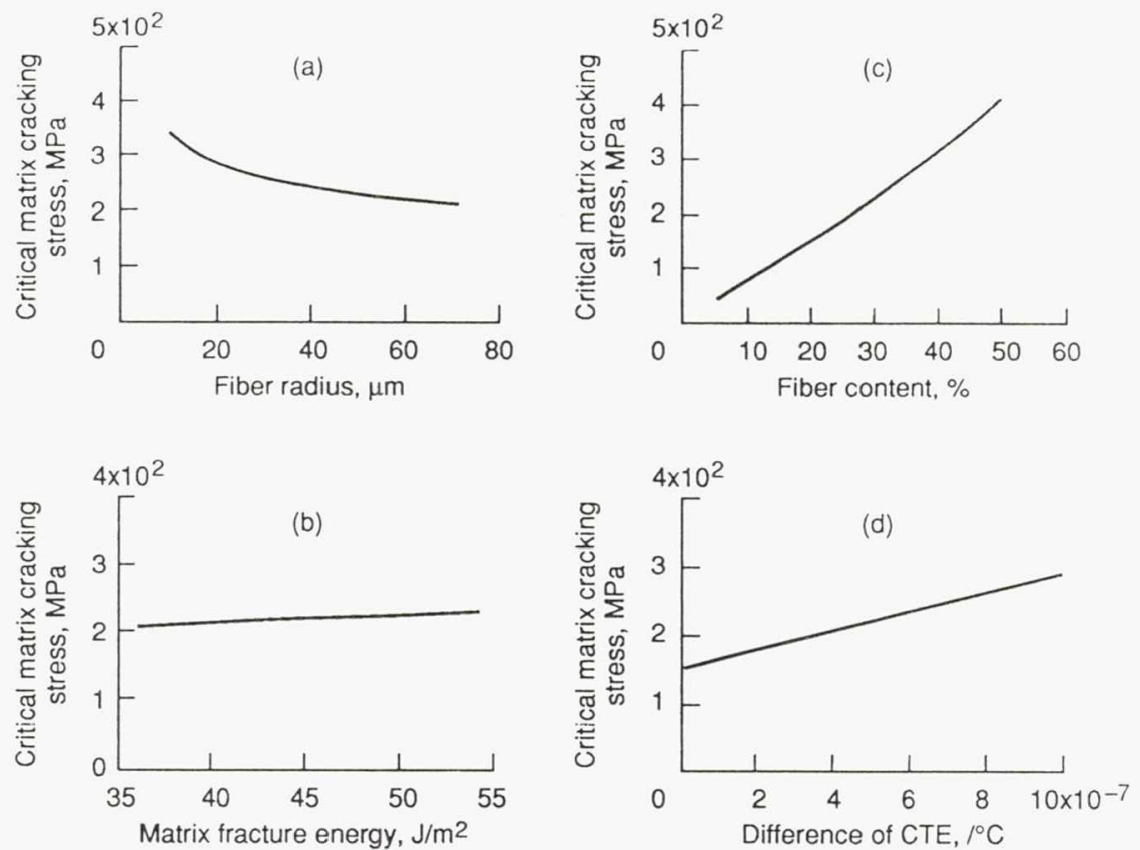

Figure 19.-Parametric studies of critical matrix cracking stress for multiple matrix cracking (slipping fibers) case.

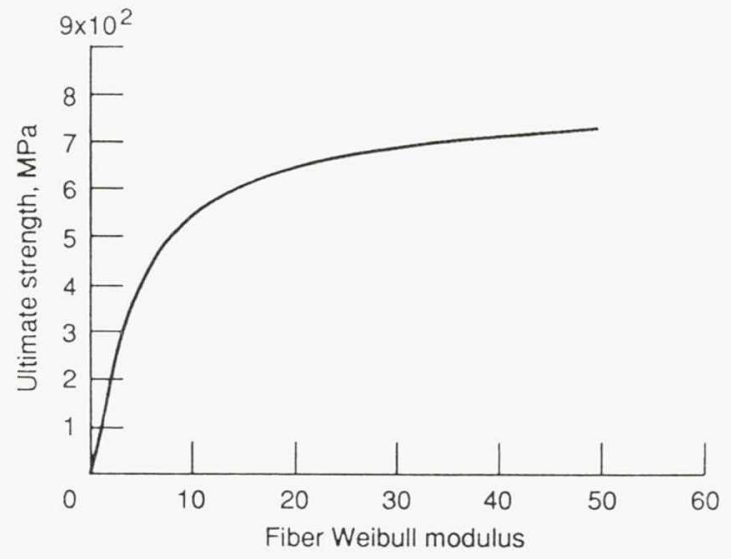

Figure 20.- Variation of ultimate strength with fiber Weibull modulus. $A_{0}=1 \mathrm{~m}^{2} ; \overline{\mathrm{S}}=2.86 \mathrm{GPa}$;

$\mathrm{L}=.1016 \mathrm{~m} ; \mathrm{f}=0.28 ; \tau=10 \mathrm{MPa}$.

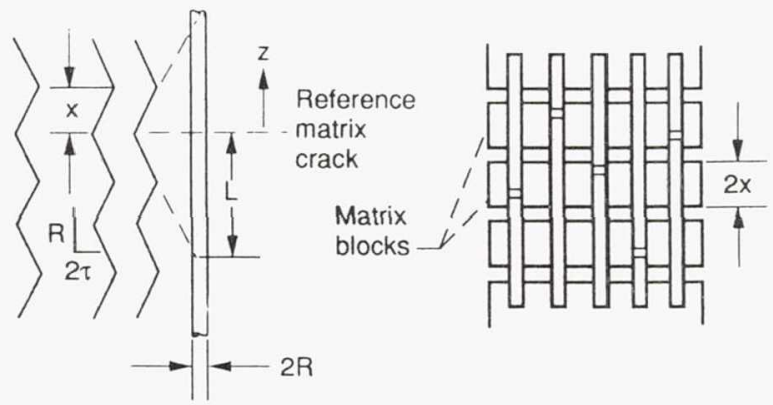

Figure 22.-Fiber stress distribution in a multiple matrix crack composite.

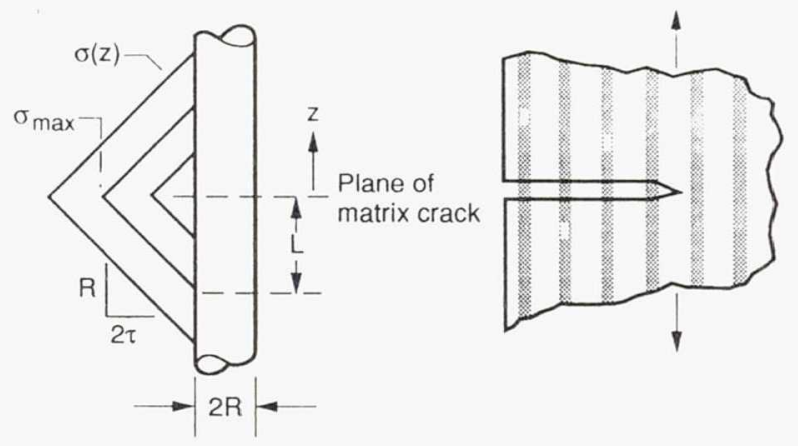

Figure 21.-Fiber stress distribution near a single matrix crack.

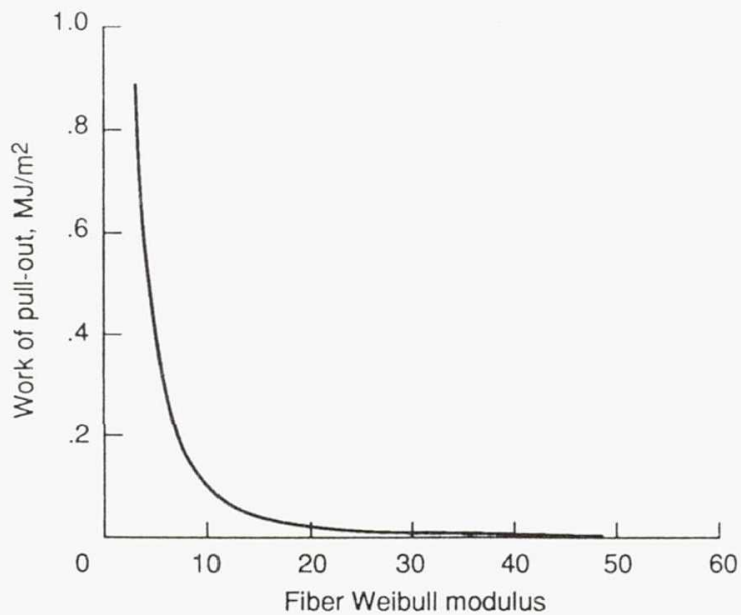

Figure 23.-Variation of work of pull-out with fiber Weibull modulus for single matrix cracking. 


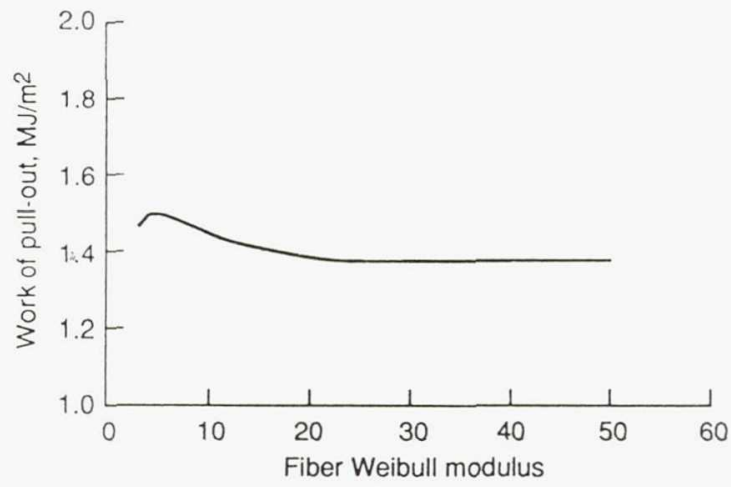

Figure 24.-Variation of work of pull-out with fiber Weibull modulus for multiple matrix cracking (slipping fibers) case.

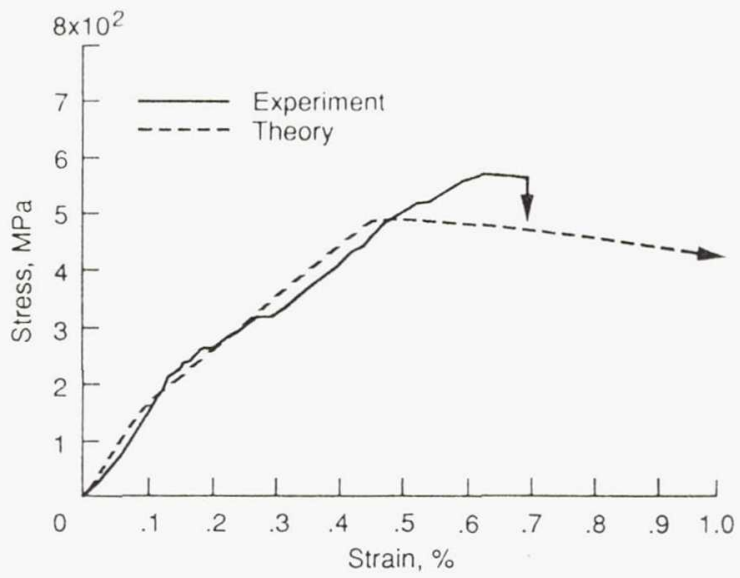

Figure 25.-Stress-strain curves for specimen M8A. 


\begin{tabular}{|c|c|c|c|c|}
\hline \multicolumn{5}{|c|}{ Report Documentation Page } \\
\hline $\begin{aligned} \text { 1. Report No. } & \text { NASA TM-103688 } \\
& \text { AVSCOM TR } 91-\text {-C-004 }\end{aligned}$ & \multicolumn{2}{|c|}{ 2. Government Accession No. } & \multicolumn{2}{|c|}{ 3. Recipient's Catalog No. } \\
\hline \multicolumn{3}{|c|}{ 4. Title and Subtitle } & \\
\hline \multicolumn{3}{|c|}{$\begin{array}{l}\text { Mechanical Behavior of Fiber Reinforced SiC/RBSN Ceramic } \\
\text { Matrix Composites: Theory and Experiment }\end{array}$} & \multicolumn{2}{|l|}{ 5. Report Date } \\
\hline \multicolumn{3}{|c|}{ Abhisak Chulya, John P. Gyekenyesi, and Ramakrishna T. Bhatt } & \multicolumn{2}{|l|}{ E-5907 } \\
\hline \multirow{2}{*}{\multicolumn{3}{|c|}{ 9. Performing Organization Name and Address }} & \\
\hline & & & \multicolumn{2}{|c|}{$510-01-50$} \\
\hline \multicolumn{3}{|l|}{ NASA Lewis Research Center } & \multicolumn{2}{|c|}{ 1L161102AH45 } \\
\hline \multirow{2}{*}{\multicolumn{3}{|c|}{$\begin{array}{l}\text { Cleveland, Ohio } 44135-3191 \\
\text { and } \\
\text { Propulsion Directorate } \\
\text { U.S. Army Aviation Systems Command } \\
\text { Cleveland, Ohio 44135-3191 }\end{array}$}} & \multicolumn{2}{|c|}{ 11. Contract or Grant No. } \\
\hline & & & \multirow{2}{*}{\multicolumn{2}{|c|}{$\begin{array}{l}\text { 13. Type of Report and Period Covered } \\
\text { Technical Memorandum }\end{array}$}} \\
\hline \multirow{2}{*}{\multicolumn{3}{|c|}{$\begin{array}{l}\text { 12. Sponsoring Agency Name and Address } \\
\text { National Aeronautics and Space Administration } \\
\text { Washington, D.C. 20546-0001 } \\
\text { and } \\
\text { U.S. Army Aviation Systems Command } \\
\text { St. Louis, Mo. } 63120-1798\end{array}$}} & & \\
\hline & & & 14. Sponsoring $\mathrm{AC}$ & Code \\
\hline \multicolumn{5}{|c|}{ 15. Supplementary Notes } \\
\hline \multicolumn{5}{|c|}{$\begin{array}{l}\text { Prepared for the 36th International Gas Turbine and Aeroengine Congress and Exposition sponsored by the } \\
\text { American Society of Mechanical Engineers, Orlando, Florida, June 3-6, 1991. Abhisak Chulya, Dept. of Civil } \\
\text { Engineering, Cleveland State University, Cleveland, Ohio } 44115 \text { (work funded by NASA Cooperative Agreement } \\
\text { NCC3-81) and NASA Resident Research Associate. John P. Gyekenyesi, NASA Lewis Research Center. } \\
\text { Ramakrishna Bhatt, Propulsion Directorate, U.S. Army Aviation Systems Command. Responsible person, } \\
\text { John P. Gyekenyesi (216) 433-3210. }\end{array}$} \\
\hline \multicolumn{5}{|l|}{ 16. Abstract } \\
\hline \multicolumn{5}{|c|}{$\begin{array}{l}\text { The mechanical behavior of continuous fiber reinforced SiC/RBSN composites with various fiber contents is } \\
\text { evaluated. both catastrophic and noncatastrophic failures are observed in tensile specimens. Damage and failure } \\
\text { mechanisms are identified via in-situ monitoring using NDE techniques through the loading history. Effects of } \\
\text { fiber/matrix interface debonding (splitting) parallel to the fibers are discussed. Statistical failure behavior of fibers } \\
\text { is also observed, especially when the interface is weak. Micromechanical models incorporating residual stresses to } \\
\text { calculate the critical matrix cracking strength, ultimate strength and work of pull-out are reviewed and used to } \\
\text { predict composite response. For selected test problems, experimental measurements are compared to analytical } \\
\text { predictions. }\end{array}$} \\
\hline \multirow{2}{*}{\multicolumn{2}{|c|}{$\begin{array}{l}\text { 17. Key Words (Suggested by Author(s)) } \\
\text { Ceramic matrix composites; Tension test; Acoustic } \\
\text { emission; X-radiograph; Micromechanical models; } \\
\text { Residual stress; Steady-state matrix cracking stress; } \\
\text { Ultimate strength; Work of pull-out; Weibull parameter }\end{array}$}} & \multirow{2}{*}{\multicolumn{3}{|c|}{$\begin{array}{l}\text { 18. Distribution Statement } \\
\text { Unclassified-Unlimited } \\
\text { Subject Categories } 24 \text { and } 39\end{array}$}} \\
\hline & & & & \\
\hline $\begin{array}{l}\text { 19. Security Classif. (of this report) } \\
\text { Unclassified }\end{array}$ & $\begin{array}{l}\text { 20. Security Classif. } \\
\text { Un }\end{array}$ & $\begin{array}{l}f \text { this page) } \\
\text { assified }\end{array}$ & $\begin{array}{l}\text { 21. No. of pages } \\
28\end{array}$ & $\begin{array}{r}\text { 22. } \text { Price }^{*} \\
\mathrm{~A} 03\end{array}$ \\
\hline
\end{tabular}

